\title{
HANDMADE PAPER: A REVIEW OF ITS HISTORY, CRAFT, AND SCIENCE
}

\author{
Martin A. Hubbe ${ }^{\mathrm{a} *}$ and Cindy Bowden ${ }^{\mathrm{b}}$ \\ For over 2000 years the manual craft of papermaking has been practiced \\ all over the world utilizing a variety of techniques. This review describes \\ the evolution of hand papermaking and its cultural significance. Paper's \\ evolution has been shaped by the structure and chemical composition of \\ the fibers. Almost every aspect of modern papermaking technology has \\ been foreshadowed by traditional practices. Such practices were passed \\ down for many generations within families of papermakers. The main \\ sources of cellulosic fiber evolved as the ancient craft migrated from its \\ birthplace in China to Korea and Japan, the Islamic world, and then to \\ Europe and America. Though most paper made today comes from \\ automated, continuous production systems, handmade paper has \\ enjoyed a resurgence, both as a traditional craft and as an art-form. In \\ addition, traditional papermaking methods can provide insights to help in \\ modern applications involving cellulosic fibers.
}

Keywords: Handmade paper; History; Handcraft; Science; Cellulosic fibers

Contact information: a: Department of Forest Biomaterials; North Carolina State University; Campus Box 8005; Raleigh, NC 27695-8005 USA; b: Robert C. Williams American Museum of Papermaking, Inst. of Paper Science and Technology, Mail Code 0620, Georgia Tech., Atlanta, GA 30332-0620;

*Corresponding author: hubbe@ncsu.edu

\section{INTRODUCTION}

Whenever people engage their hands and minds to make paper, there is a continuing opportunity for evolution of the craft. Each maker adopts or selectively omits parts of the methods that have been passed down to them, sometimes inventing new techniques. It has been said that deep down, every papermaker believes that her or his own procedure is the way to make paper by hand (Heller 1978). The irony of the situation, however, lies in the fact that hand papermaking through the ages has gravitated toward a handful of procedures that seem to work well - in contrast to methods that simply have not stood the test of time. Our goal is to consider the ways in which the evolution of handmade paper technology has been influenced by the nature of the cellulosic material itself.

The present review article owes much to the work of Dard Hunter (1947), who has helped ignite modern interest in this ancient subject. As noted by Baker (2000), Hunter appreciated the enormity of paper's contribution to humankind, the range of its qualities, the social aspects of its production, its importance to the spread of technology and religious thought, and even its relationship to the fine arts. 


\section{Influence of Paper on Human Culture}

Papermaking as a story of personalities

When browsing through old books dealing with handmade paper, one frequently encounters colorful characters (Stromer 1390; Hunter 1930, 1947; Birch et al. 19641965; Heller 1978; Premchand 1995). Popular literature often characterizes Cai Lun of China as being the inventor of paper in the year 105 AD (Hunter 1947). One can read about the Korean Buddhist monk Danshó, who came to Japan in 610, bringing knowledge of the art of papermaking. Using this invention, the empress Shotoku is said to have sponsored and possibly invented the first printing in the year 770 (Anon. 1962). The truth is that the real progress of papermaking technology has depended on countless craftspeople. A focus on just a few "heroes" of the craft places insufficient attention on the unrecorded artisans who have sustained and developed the craft, bringing about the emergence of the traditional practices and regional characteristics of handmade papermaking practices and its products.

\section{Papermaking as a family and guild endeavor}

Traditional papermaking usually has been practiced by a family, village, or guild (Tindale and Tindate 1952; Goto 1953; Schleider 1993; Barrett 2005). Within these groups there was a balance between individual specialization and some activities, such as the beating of pulp, in which the whole group might be called upon to work together. Hand papermakers have a considerable appreciation for carrying out activities in certain seasons, and also respecting the whims of the weather. Fall proved to be a good time to harvest paper mulberry (kozo) for fibers, and the mucilage used frequently by papermakers in the East had a much lower rate of fermentation if used in the colder months of winter (Longenecker 1985). During winter, many traditional farming families made paper to supplement their income. Social hierarchies have had their own impact on traditional papermaking, considering the fact that some of the finest products of the trade have served the needs of political and religious elites (Berliner 1986).

\section{Sustainability and social responsibility}

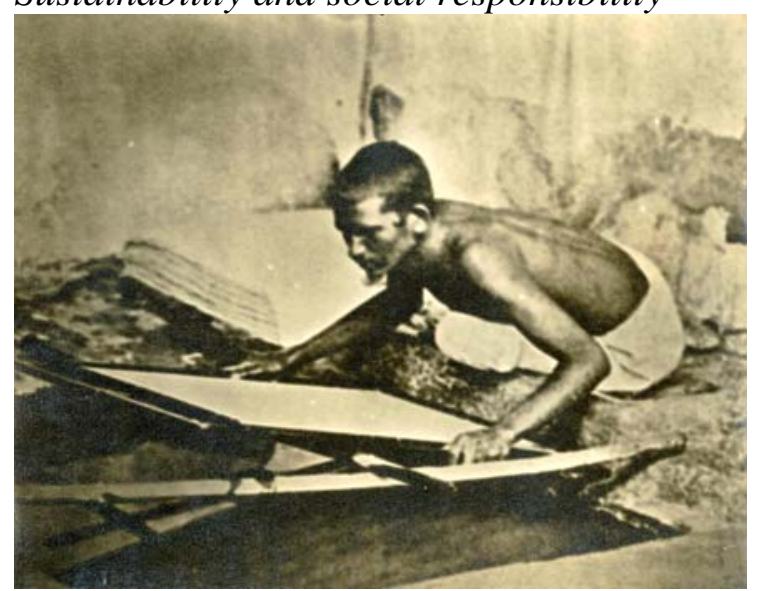

Fig. 1. Photo by Dard Hunter of papermaker pulling a sheet, Sailkot, Punjab, India
Increasing attention is being paid to the positive role that traditional crafts can play in society (Biggs and Messerschumidt 2005). Traditional papermaking generally employs renewable resources, can be carried out in such a way as to avoid polluting the environment, and can help bind communities and social groups together. Taori (2002) has proposed that the hand papermakers take further steps to become a more truly eco-friendly industry. There also has been some considerable effort to achieve goals related to national identity through activities that included hand papermaking. 
Gandhi called for Indians to return to their traditional cottage industries, including their hand papermaking traditions. Fibers made from waste crops and waste paper resources can provide societal benefits, including rural employment (Mcfarlane 1993; Premchand 1995).

\section{Paper as an aid or substitute for memory}

Another way that paper has transformed society is by supplementing human memory. Scholars of preliterate peoples have remarked about the importance of memorizing essential information. For centuries, paper has been competing with the human mind - and now with the computer - as a preferred means of storing knowledge. Memory systems based on writing have proven advantageous, especially when it is important to retain the facts reliably for long periods of time or among large numbers of people (Bloom 2001).

\section{The psychology of making paper by hand}

The relationship between the mind and hand papermaking becomes apparent when one examines the motivations behind adopting traditional papermaking as a passion. The sheer amount of effort required to achieve, by manual labor, what can be achieved more efficiently with modern machinery can be sometimes viewed by friends and strangers as evidence of insanity (Heller 1978). That is not to say that all papermakers are insane, at least not all in the same way; one of the unique aspects of papermaking is that one individual may, if they wish, control the entire process (Kern 1980). Thus, there is ample opportunity for the personality of the individual papermaker to show in their work, and many papermakers put some of themselves into each sheet. Hand papermakers also help to preserve the heritage of their craft (Patakfalvi 2005). Even though the process is labor-intensive, the result is invaluable.

Purists should be warned that a distinction can be made between "handmade" vs. "formed on a mold" paper. By means of automation it is possible to mechanize almost anything, including some of the actions of a traditional papermaker (Turner and Skiöld 1983). Important progress in this direction was pioneered by a true hero of human culture, Mahatma Gandhi, whose papermaking assistant Krishna Joshi introduced various innovations that have led India to emerge as one of the most important sources of handmade and mold-made papers in the present era. For example, Joshi adopted an approach developed earlier in China and Japan, using a pulley system to compensate for the weight of the large forming device. Some of the sheets are run through calendering nips between steel rolls, thus borrowing from machine-papermaking technology. Indeed, every hand papermaker may have to establish their own definition of what they can consider to be "appropriate technology

Psychology also may explain the slowness with which papermaking technology gradually spread from its birthplace in China across the Silk Road to the Islamic world, and from there rather slowly through Europe and beyond. It was roughly 500 years after the documented establishment of papermaking in China that the first records of the craft appeared in Korea and Japan (Hunter 1947) followed by papermaking spreading to Samarkand, Persia (Iran), and the Arab world in the late Eighth Century. It took yet another 400 years or so for papermaking to reach Europe. Heller (1978) attributed the 
very slow spread of the technology to paper's humble qualities as a relatively weak, ephemeral, and cheap product. Even at the time of paper's invention, it is likely that one of the main motivations was to find a cheaper writing surface than expensive silk cloth (Hunter 1947). In addition, papermakers have tended to be secretive. Each group of papermakers wanted others to purchase paper, not to become competitors.

\section{The diversity of handmade paper products}

Paper has had a wide variety of uses across time. One of the most famous events was in the construction of balloons launched from Japan during the Second World War (Hunter 1947; Barrett 2005). The ability of such balloons to cross the Pacific Ocean would not have been possible without great care in selecting and preparing strong bast fibers, forming defect-free sheets having a ply structure (see descriptions of the nagashizuki method), and innovative surface treatment with oil to make the balloon air-tight and resistant to water. Papermakers were selected from the villages and inducted into the army to make the balloons.

Other uses of handmade papers have included ceremonial paper, where colorfully printed paper stood in place of depicted offertory items, including money (Hunter 1937). Today ceremonial money includes depictions of clothing, eye glasses, cars, and even credit cards.

In Japan handmade paper has been used to make umbrellas, fans, screens for windows, and lacquered strings composed of twisted paper, or "shifu" (Jugaku 1959). Figure 2 shows how thin strips of paper (left side) can be progressively twisted into yarn (lower right) and then made into textiles (upper right). Shifu has been used for knitted and woven items, baskets, mats, bags, clothing, and art objects (Bunshō 1959; Barrett 2005; Leitner 2005).

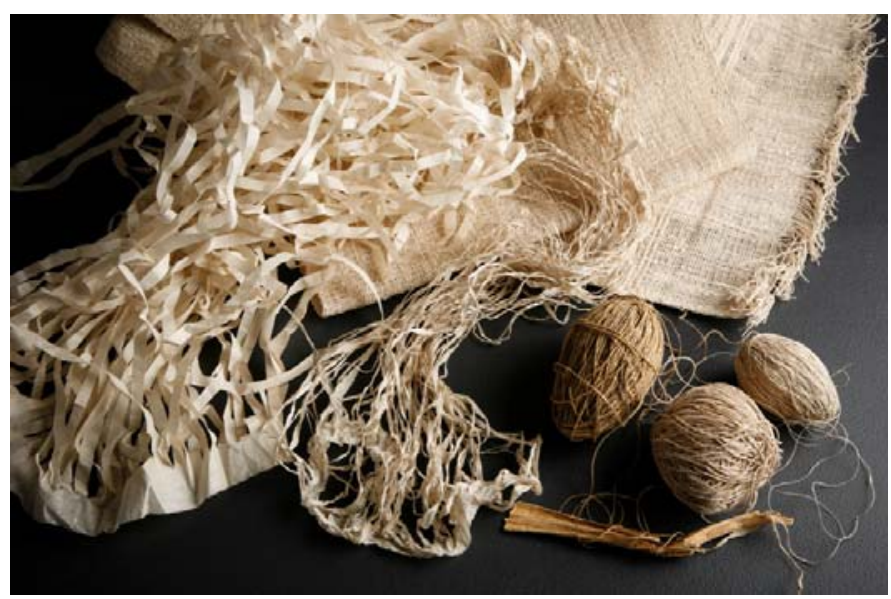

Fig. 2. Stages of making Shifu, Courtesy of Deepak Sheestra, 2008.

Other uses of Japanese handmade papers have included fireworks, books, kites, calligraphy paper, letters, envelopes, bags, lanterns, and, of course toilet paper (Longenecker 1985; Barrett 2005). Omae (2005) has collected examples of print designs that have been applied to handmade wrapping paper and other items by means of wood block printing, called chiyogami. When handmade paper spread to the Islamic world, it was used for writing, wrapping, painting, offerings, clothing, kites, sanitary uses, and also playing cards, a tradition that can be traced back to the Chinese (Bloom 2001). In modern times, in addition to the other traditional uses, handmade paper has been used for greeting cards, journals, and increasingly for artistic purposes (Garner 2006). 


\section{The Tension between the Craft and the Art}

Skillful crafters of handmade paper take pains to develop techniques that produce a uniform product. In most cases the papermaker's goal is to achieve uniformity, as well as adherence to a set of expected attributes. By contrast, no constraining rules can be written for art; a piece of art is intended to have a unique interaction with the observer (Heller 1978).

Paper art can be made with paper, or sometimes it is the paper, especially if the paper is manipulated in some manner (Fig. 3). For instance, the paper's receptivity toward ink, as well as the appearance of texture or grain that stands out when ink is applied, can depend on the type of fibers, how the paper was prepared, and various posttreatments (Webb 1982). Some common means of manipulating paper for artistic purposes include tearing, cutting, folding, mutilating, burning, scorching, stamping, casting, rolling, crumpling, sawing, painting, recycling, burnishing, and weaving (Heller 1978). The demarcation line between craft and art also depends on the selfidentification of the craftsman or artist. For instance, what if a paper artist makes a piece that really appeals to them and then replicates it? Is the act of making the second object "art" or is it "craft"? Or, as in the prologue to Studley's (1977) book, is "papermaking ... an artistic craft"?

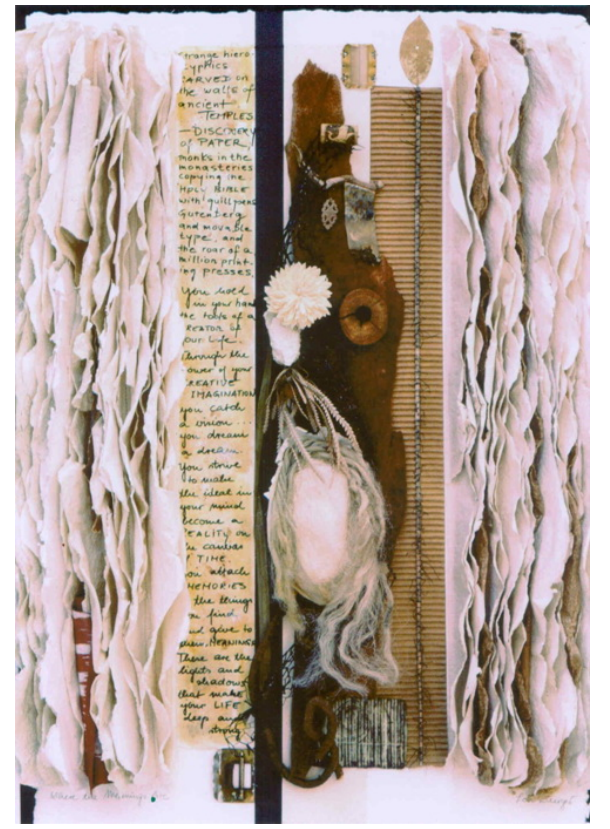

Fig. 3. Paper art by Lore Burger, "Where are the meanings?"

Mixed media with handmade paper 2000

\section{Papermaking's secretive nature}

A common strategy to maximize profit in papermaking was to keep one's procedures secret, thereby maintaining a monopoly, or at least a competitive advantage. For example, one of the earliest first-person accounts of a handmade papermaking enterprise comes from a document left by Ulman Stromer (1390). He recruited a team of papermakers from Italy to Germany and made them swear not to share their knowledge with any of his potential competitors. The admonition backfired, however, since the workers understood the value of their knowledge. The monopoly was broken, and the local price of paper soon fell. As another example, artisans who prepare marbled paper (see Marbling) have been noted to be especially secretive (Wolfe 1990). In fact, when Woolnough (1881) published the first edition of a book on marbling, other marblers complained that he had given away the secrets of the trade.

Enter the age of "how to"

Even before the emergence of the Internet, hand papermaking has been entering a new age of openness. One sign of this openness has been a series of "how to" books (Studley 1977; Heller 1978; Kern 1980; Aytüre-Scheele 1986; O’Reilly 1993; Dawson and Turner 1995; Smith 1995; Plowman 1997; Ramsay 1999; Reimer-Epp 2000; Lee 
2001; Ackerson 2003; Hiebert 2000). These books reflect not only of a resurgence of interest in handcrafts, but also a desire to engage young children and adults The publication of limited-edition descriptions of the history of papermaking by Clapperton (1934) and Hunter (1923, 1927, 1930, 1932, 1936, 1937, 1939) as well as Hunter's 1947 mass-market book inspired succeeding generations of papermakers (Turner 1998). The majority of Hunter's books were hand typeset on handmade paper with artifacts mounted or tipped within them as examples.

\section{HISTORICAL SUMMARY AND KEY EVOLUTIONARY BRANCHES}

The evolution of papermaking methods has been strongly influenced by the structural and chemical features of the cellulosic fibers. Before attempting to discuss the role of cellulose fiber characteristics in this evolution, our first task will be to provide the context. The following will outline some major traditions and innovations associated with major historical centers of papermaking activity.

\section{Predecessors of Paper}

The unique nature of paper can perhaps best be appreciated by considering some closely related traditional practices. Ancient civilizations have had a number of ways of converting various cellulosic materials into writing surfaces and articles of clothing, many of which did not require weaving (Anon. 1962; Bell 1983; Bloom 2001). These products have been formed from bark (amate and tapa), from reeds (papyrus), and from palm leaves. None of these items involve separating the cellulosic fibers completely from each other and dispersing them in water before preparation of the product (Longenecker 1985).

Fabric is another predecessor of paper, especially as a possible substrate for writing. Cotton, for instance, is almost pure cellulose. As noted by Bloom (2001) there are fragments of a silk map dating from the $2^{\text {nd }}$ century B.C. Distinguishing characteristics of a textile product include the spinning of yarns and subsequent weaving of the yarns together, two processes that are not used in forming a sheet of paper. Papermaking dates back to approximately 200 BCE.

\section{Bark}

The use of bark as a writing surface and for items of clothing was widespread in many cultures (Hunter 1927; Van Hagan 1944; Anon. 1962; Tsien 1973; Bell 1983). Hunter visited Mexico and the Pacific islands and watched as the residents pounded the inner bark into tapa and amate. The pounding stretched the bark and imparted desired qualities of flexibility and smoothness. Such practices were developed to a high level by the Mayans, who produced 45-page codices (Anon. 1962). As noted by Tsien (1973), tapa also was pounded into clothing by people to the south and west of the Chinese inventors of papermaking, and such practices even might have served as an evolutionary link, making it evident to early Chinese papermakers that bark could be used as a source of fibers for papermaking. Amate is pounded bark from Mexico (see Fig. 4). Amate is distinguished from ordinary tapa by the use of a cooking process (Bell 1983). 


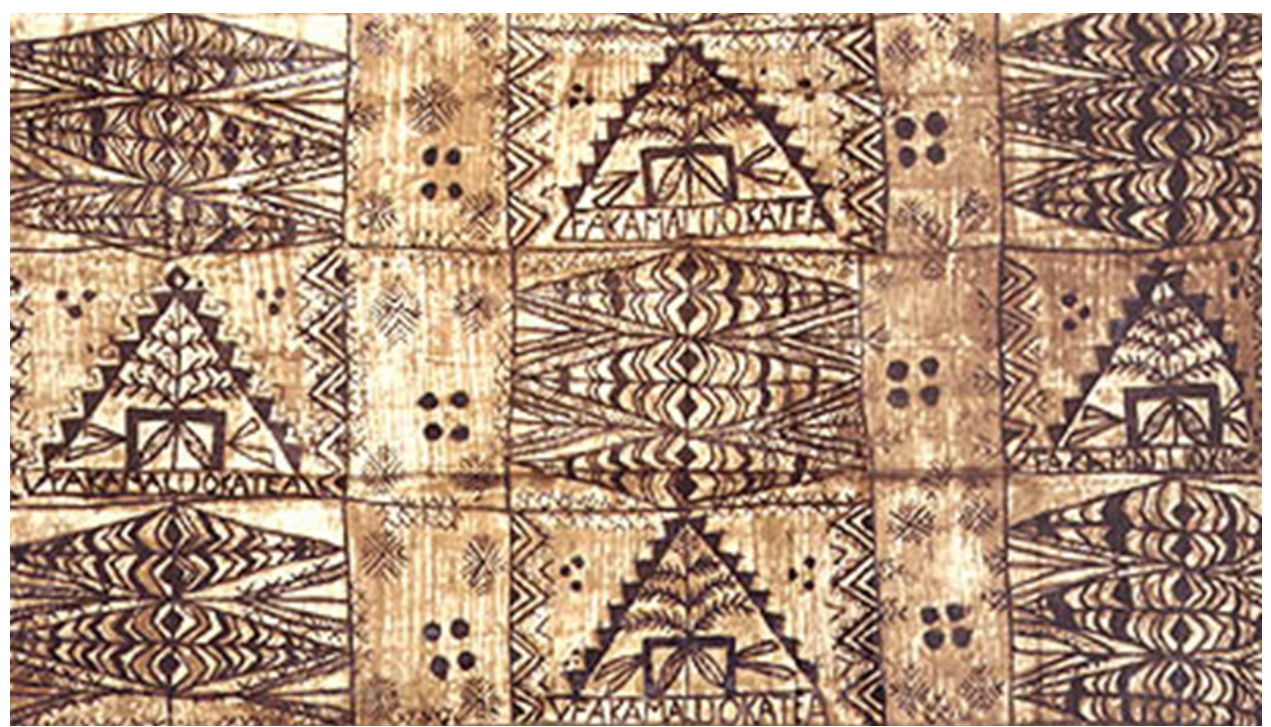

Fig. 4. Example of decorated tapa obtained from the pounding of bark (Robert C. Williams American Museum of Papermaking)

Though the adjacent fibers do not become fully separated from each other in the forming of tapa, there is an interesting similarity with paper processing. The traditional method of refining fibers for papermaking also involves a pounding action, and it is reasonable to expect that the resulting hydration and swelling of the cellulosic material was similar in each case. The considerable stretching of tapa during its preparation is consistent with a process of internal fibrillation of the cellulose, and it is reasonable to assume that some fiber-to-fiber attachments are broken during the pounding.

\section{Rice paper}

Rice paper, which is more properly called "pith paper" is not paper at all, and it has nothing to do with rice, with the possible exception of its color (see Fig. 5). The material is prepared by careful cutting of the pith of the kung-shu plant (Tetrapanax

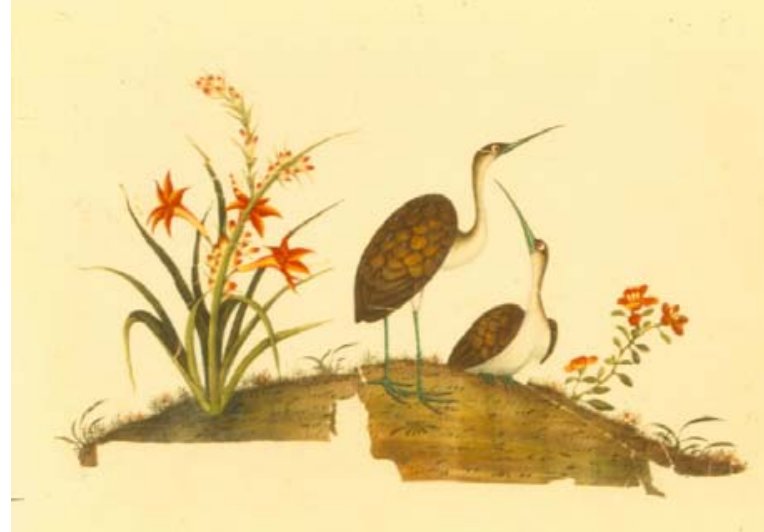

Fig. 5. Sample of kung shu, commonly known as rice paper, China ca. 1930 papyrifera), which is native to China (Anon. 1962). Whereas paper is formed mainly from cellulosic fibers or tracheids, which are usually $1 \mathrm{~mm}$ or more in length, the pith is mainly comprised of the much smaller and less fibrillar parenchyma cells. These cells are used by plants for food storage, rather than for structure, so it is unsurprising that rice paper lacks the strength of conventional paper. 


\section{Papyrus}

The common features of cellulosic material and pounding are shared with paper by papyrus (De Lalande 1761; Anon. 1962; Bell 1983; Bloom 2001). A papyrus writing surface is prepared by lining up a row of reeds, which have been horizontally slit down the middle, then adding another row, perpendicular to the first. These are pounded together and dried. As in the case of paper, the cellulosic material becomes held together by the formation of numerous hydrogen bonds (McGovern 1982). Papyrus was widely used as a writing surface not only in Egypt (Lewis 1983; Wiedenmann and Bayer 1983), but throughout the Islamic world, as well as in the lands around modern-day Israel. Though papyrus can be rolled up in scrolls, it does not form as good a cut edge, and its fold characteristics do not lend themselves as well to the book format.

\section{Vellum and Parchment}

One of the early competitors to paper, especially in medieval Europe, was not made from cellulosic material but from animal hides. Writing media from animal hides were used in Europe as early as the $2^{\text {nd }}$ century (AD) (Blum 1934; Bloom 2001). The animal skin was cleaned, stretched on a frame (see Fig. 6), and then scraped with a curved knife to form parchment. Often the skin was split into two layers, and the resulting thinner, high-valued sheets were called vellum.

Emperor Frederick II, the emperor of the Holy Roman Empire, declared paper illegal as a medium for recording laws and official documents. One theory is that he owned a lot of sheep and cattle and did not want to lose the revenue from this source. The church hierarchy in Europe preferred the use of vellum, rather than papyrus or paper, due to its strength. Paper was associated with Islam and Judaism. The printing of the first Gutenberg Bibles proved to be a turning point in favor of paper.

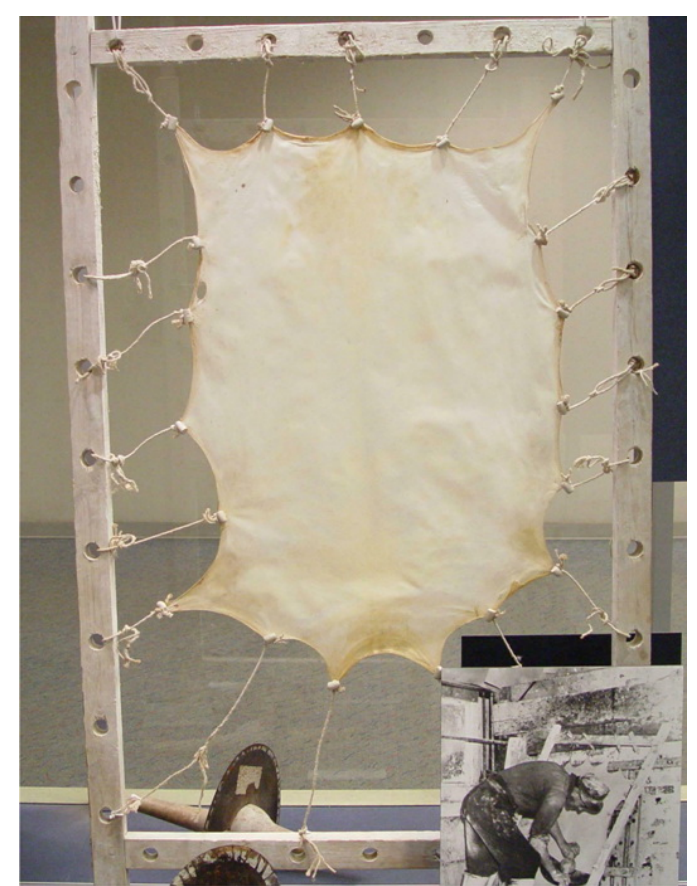

Fig. 6. Example of the spreading of animal skin in the preparation of parchment or vellum (Robert C. Williams American Museum of Papermaking, Europe)

Perhaps because there were insufficient supplies of vellum available, most of the print run was done on paper, which thereafter became a preferred medium for printed books (Bloom 2001).

\section{Hand Papermaking in China}

Due to the ravages of time, insects, fire, purges, and neglect, it is reasonable to expect that any evidence regarding papermaking practices of early China represent an incomplete remnant from a burgeoning enterprise. According to Tsien (1973), very early Chinese papers were made from hemp, jute, flax, ramie, rattan, paper mulberry (kozo), 
mulberry, and bamboo fibers. As far as is known, various plants were first soaked, allowing the bark to be stripped easily, and certain inner layers of the bark provided a source of relatively lignin-free fibers. The latter were liberated by soaking the selected layers of bark for one or more days in a solution of lye, prepared from wood ashes, followed by beating of the wet cellulosic material with a wooden mallet. Hunter (1932) reproduced a series of prints by T'ien Kung K'ai that were published in 1639, showing some of the many steps involved in the tradition of Chinese papermaking.

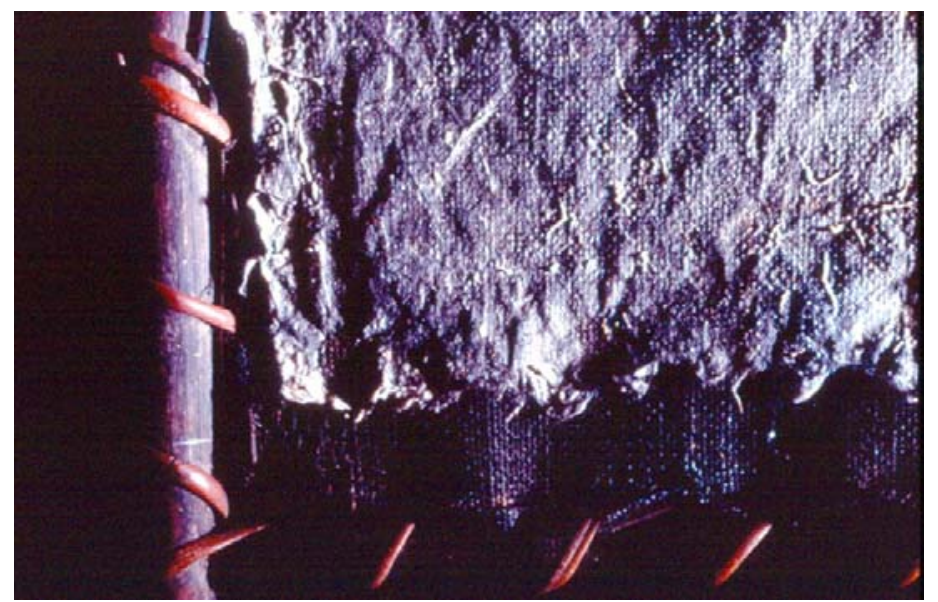

Fig. 7. Example of a wove mold, as may have been used by the earliest papermakers. In this example a dried paper sheet is still attached. (Photograph from the collection of the Robert C. Williams American Museum of Papermaking)
The earliest paper sheets are thought to have been made using a wove mold. The mold was formed from fabric stretched onto a rectangular bamboo frame (Fig. 7). This type of mold is still used in some locations, mostly to produce paper for cigarettes or wrapping paper. The mold was placed on top of water and pulp was poured on top of the mold and spread out by the papermaker. Then the mold was placed out in the sunshine to dry.

As papermaking advanced technologically, a new type of mold was developed, which the Japanese called the sugeta. The screen was prepared from narrow parallel strips of bamboo or tiny reeds (Pietzcker 2009), woven together at intervals with silk threads or horsehair. Figure 8 shows examples of such molds.
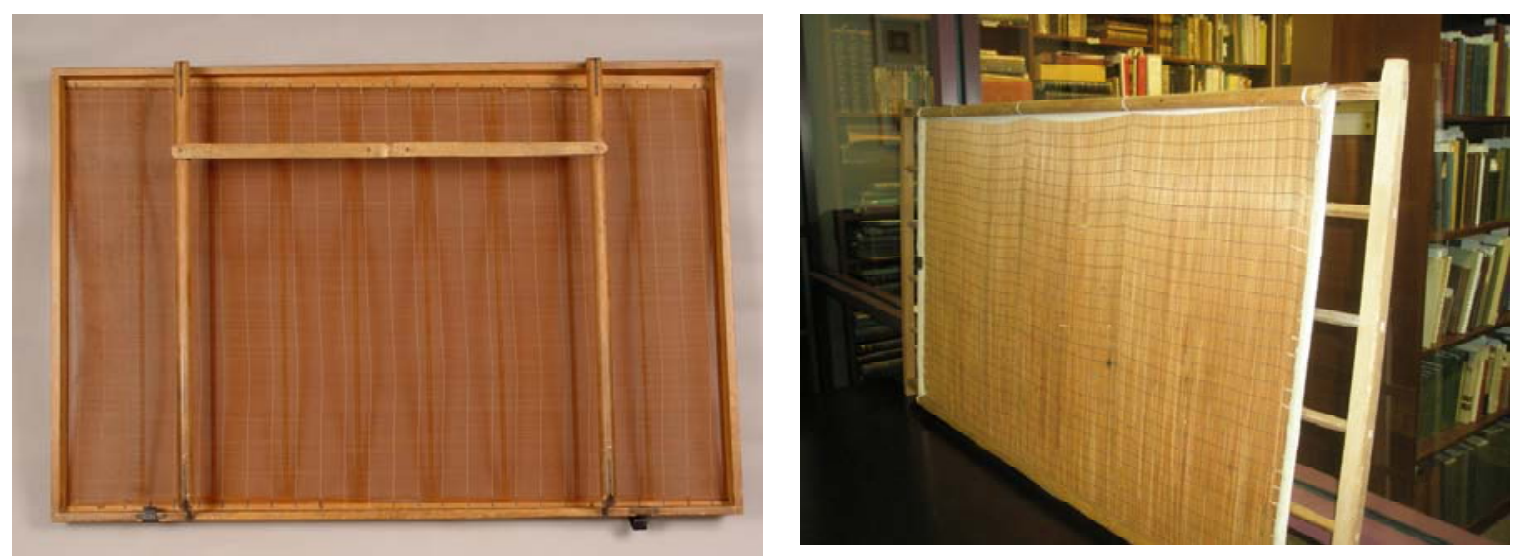

Fig. 8. Examples of sugeta molds. The mold on the left is from Japan, ca. 1920s Gifu Prefecture, Japan The mold on the right is from Korea, ca. 1920s, Ompei, Korea. (Photographs from the collection of the Robert C. Williams American Museum of Papermaking) 
To form a sheet, the fibers are suspended in water in a vat, into which the papermaker places the sugeta. The water runs between the reeds or bamboo strips as the paper is formed. Because the screen can be rolled in the direction perpendicular to its elements, it is easy thereby to transfer wet sheets of paper either onto a pile of paper or onto a flat piece of wood or a plaster wall. By transferring each sheet in a rolling manner, the screen can almost immediately be used to dip another sheet. When using the tamesuzi method, the papermaker dips the mold into a vat of fiber suspension, draws the mold toward themselves, and turns it horizontal, allowing water to drain.

\section{The Story of Cai Lun}

According to Chinese records the court official Cai Lun gave a report to the emperor He Di in 105 A.D. describing the improved preparation of paper from waste fibers, including discarded cloth and fishnets, as well as from bark and from hemp (Anon. 1962; Bloom 2001). These materials were macerated with a mortar and wooden pestle to soften and liberate the fibers. The Chinese character used to form the word "paper" contains the radicals for "silk" and for "family," suggesting that the scribes who first recorded this word considered paper to be related to cloth (Hunter 1932).

\section{Archeological finds}

Evidence suggests that the invention of paper took place a few hundred years earlier than the date attributed to Cai Lun (Koretsky 2009). An historical account set in 93 BCE described the use of paper as facial tissue (Bloom 2001). Hunter (1930) was aware of reports indicating that paper was made as early as 123 BCE. In 1957 a piece of ancient paper was found from the early Han dynasty, i.e. from no later than 140-87 BCE (Takeo Co. 1979). In Xian, China, paper dating from 200 BCE has been discovered. The paper was a prayer and was discovered in the brick of an adobe home. Paper of the same age has been located along the Silk Road. It is worth keeping in mind that all of these discoveries were made in desert climates, which provided at least a small chance for the paper specimens to survive and be discovered so many years later.

One of the earliest archeologists looking for early examples of Chinese paper was Aurel Stein, who in 1900 found paper Buddhist texts from the $2^{\text {nd }}$ and $3^{\text {rd }}$ centuries at Niya in Turkestan (Blum 1934; Clapperton 1934). The story is one of the heroic moments in the history of paper, and the happy outcome hinged on the trusting relationship between Stein and the monk Tao-Shih. The monk showed Stein a pile of about 500 cubic feet of paper manuscripts that were in a previously bricked-off room in the back of one of the "Caves of 1000 Buddhas." Manuscripts in the collection ranged from the years 400 to 1000 . To avoid raising concerns from the authorities - and the possible destruction of the documents - the monk carried bundles of documents secretly, during successive nights to Stein's tent, thus ensuring that at least some of the newly discovered documents became preserved and studied. All of the oldest papers in the collection exhibited "laid lines," indicating that the sheets were formed using a screen made from parallel bamboo strips or reeds woven into a rollable mat. Stein found other very early paper samples in a ruined watchtower along the Great Wall (Bloom 2001). 


\section{Religious texts for offering}

One of the main uses of the early paper produced in China was to help distribute Confucian and Daoist thoughts (Hunter 1947). Efforts to promote Buddhist ideas and ceremonial artwork are credited with spreading papermaking throughout China and into other lands (Bloom 2001). Marco Polo (1254-1323) noted the use of paper for offerings at the time of a burial (Hunter 1937). In China, ceremonial money was often burnt as a representative offering. Today ceremonial paper is still used to send money or valuable items such as credit cards, clothing, and automobiles to the ancestors. Because the paper was intended for godly purposes, it was not acceptable to use either waste paper or cloth as the source of fibers to be used for such purposes (Bunshō 1959; Jugaku 1959). As a general rule early paper products made in China generally were thin, strong relative to their weight, and absorbent. Text was applied to one side of the paper, usually with a brush (Clapperton 1934). Recent observations of traditional hand-made paper practices in China have been well documented (Yang et al. 2005; Koretsky 2009).

\section{Japan and Korea}

The craft of papermaking developed new technologies as it spread to Japan. Because paper's introduction to Japan is about 500 years later than its origins in China, the historical evidence is somewhat fresher. A set of 41 stencil prints published by Goto (1953) provides a wonderful pictorial description of the whole process. Details of Japanese traditional papermaking have been described in great detail (Bunshō 1959; Turner 1998; Barrett 2005). Though other fibers have been used, there has been a strong preference to use bast fibers from kozo, mitsumata, and gampi. The fibers were obtained by steaming the stems, stripping the bark while still hot, cleaning the bark, stripping off dark layers of bark, cooking in alkali, and relatively gentle beating to separate the long

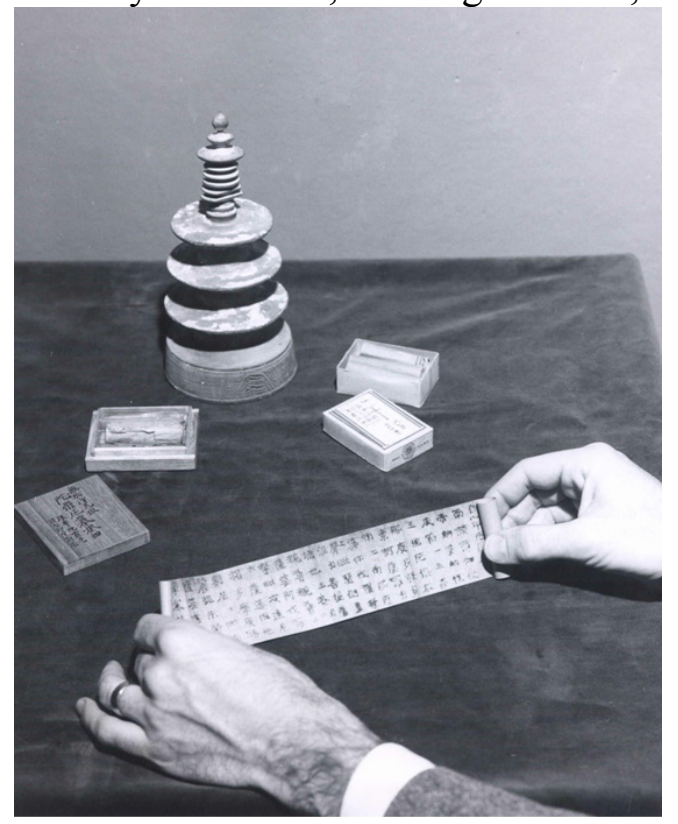

Fig. 9. Dard Hunter showing prayer and pagoda. The prayers and pagoda are from the collection of the Robert $C$. Williams Paper Museum, 770 AD, Japan). fibers (Turner 1998). The finished sheets are transferred onto a smooth wood surface, which is placed in the sun to dry.

A colorful historical event associated with the spread of papermaking technology in Japan involved the Empress Shotoku, who in the year 770 ordered the preparation of one million copies of Buddhist prayers. The prayers were woodblock printed onto strips of handmade paper and placed into carved 4.5-inch high wooden "pagodas" (see Fig. 9) that were distributed among the temples (Clapperton 1934; Hunter 1947; Anon. 1962). The prayers were either in thanks for the repression of a rebellion (Bunshō 1959), or to ask for protection against a smallpox epidemic (Hunter 1947). Whatever the reason, many of the pagodas and prayer strips have survived to the present day, providing evidence of perhaps the earliest multiple printing of text. 


\section{Nagashi-zuki}

One of the most striking, though not universal aspects of traditional Japanese handmade paper, washi, is the addition of mucilage to the water from which the paper is formed (Bunshō 1959; Hughes 1978; Barrett 1991, 2005; Hori 1991; Turner 1998). Tororo aoi, in the hibiscus family, is the most common source for making mucilage. To release the mucilage, the roots are pounded and placed in water. Figure 10 shows the roots being soaked to extract mucilage to be used during the forming of paper.

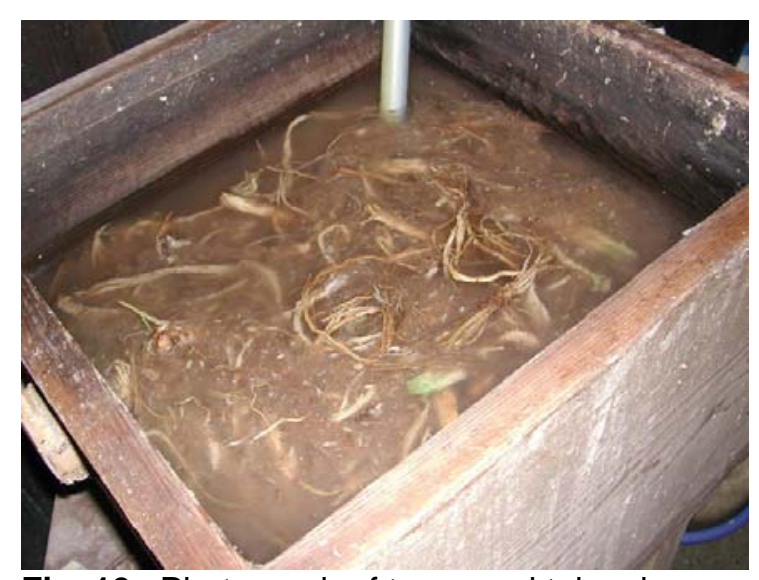

Fig. 10. Photograph of tororo-aoi taken by Cindy Bowden in Imadate Japan, 2003.

As in the case of the "formation aids" used in the modern-day preparation of wet-laid nonwoven products (Wasser 1978; Lee and Lindström 1989), the purpose of the mucilage is to keep the long fibers from forming knots and otherwise entangling with adjacent fibers to form flocs as the paper sheet is being formed. The mucilage also decreases the rate with which water drains from the fiber suspension.

By combining the use of mucilage, long fibers, and their experience making sheets, the Japanese artisans developed a special way to prepare relatively thin and strong sheets of paper. When using this method, the papermaker forces a wave of water and fibers back and forth across the screen, and usually also from side to side several times. This is shown schematically in Fig. 11. Papermakers using the nagashi-zuki method can quickly dip an edge of the mold into the fiber suspension a second or a third time to repeat the process of flowing waves of fiber suspension back and forth across the screen, thus achieving a somewhat thicker and heavier sheet of paper. Since the fibers tend to align themselves in the direction of flow, it is possible to develop an essentially multi-ply sheet in which some of the fibers are aligned at right angles to each other. As shown in the picture, more layers of paper can be applied on top of an initial layer.

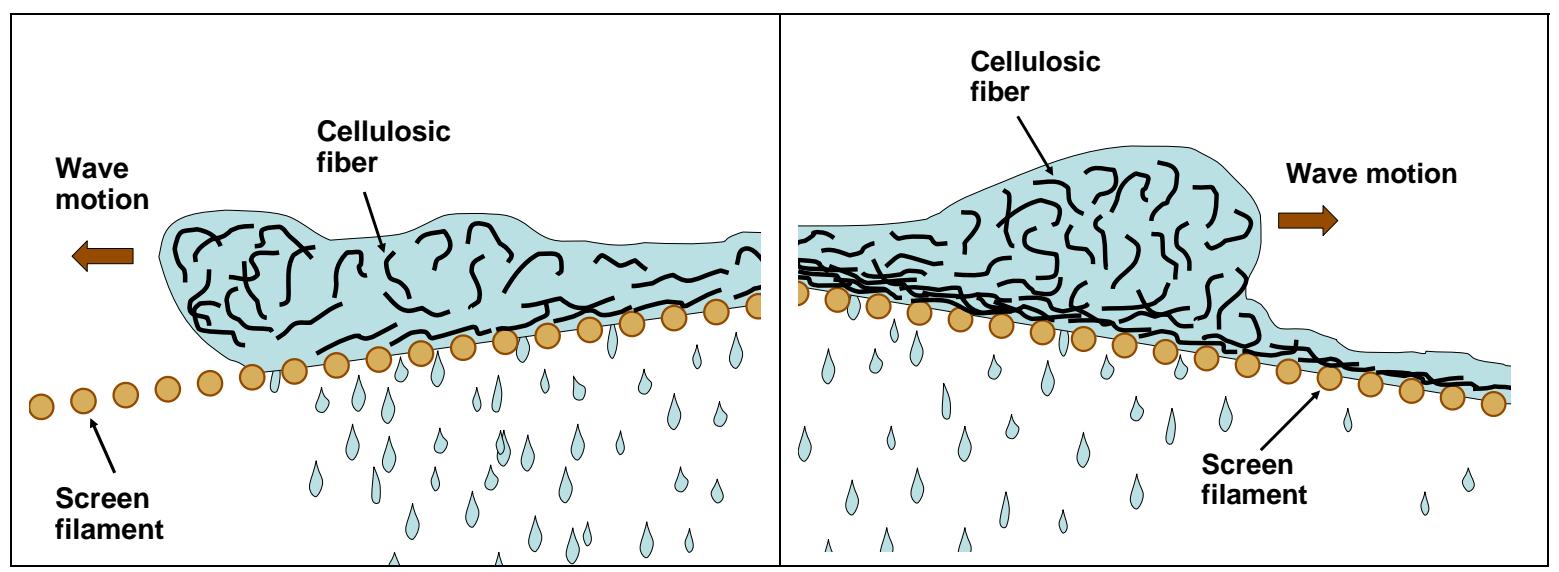

Fig. 11. Illustration of nagashi-zuki method of paper forming, in which successive waves of fiber suspension, usually prepared with a mucilaginous solution, flow over the screen surface. Left: First wave. Right: Second or later wave. 


\section{Islamic World}

Paper became well known and used along the Silk Road, the ancient overland trading route between China and the West. The pursuit and evolution of papermaking along this route and at its termini in the Islamic world has been documented (Clapperton 1934; Bloom 2001). In the year 751 the Chinese were defeated by Islamic forces in Talas (or Tharaz), a location along the Silk Road in Samarkand (Bloom 2001). According to Blum (1934), Chinese papermakers were taken prisoner and set to work in Samarkand, where there was abundant flax (Hunter 1939). Whether or not this story is true, the subsequent change in political control resulted in relatively rapid spread of the papermaking technology, acquired from Chinese papermakers, to Baghdad, and subsequently throughout the Islamic world. Paper was used in the dissemination of religious texts, this time the words of Mohammed (Bloom 2001). Paper replaced papyrus for making copies of the Koran and for general use. The transition has been traced to a decision made by religious leaders in Baghdad, who decided that paper was more suitable for folding in the codex format, i.e. books.

As paper technology became adopted by Central Asians, and also in India and Europe, the product tended to be heavier and less absorbent, making it practical to place text on both sides of a sheet. Due to the inherent difficulty in draining water from a heavy sheet (Hubbe and Heitmann 2007), a difficulty that would tend to be enhanced by the presence of significant amounts of mucilaginous polymer in the water (Toale 1983), the nagashi-zuki method did not accompany papermaking technology in its westward journey down the Silk Road. Rather, papermakers learned to size the paper sheets by dipping them into solutions of starch or gelatin after their formation, followed by drying them again.

\section{India}

Another branch of the overland trading routes extended southward from Samarkand into what is now India (see Fig. 12), where handmade papermaking became a guild craft (Hunter 1939; Mcfarlane 1993; Premchand 1995; Soteriou 1999). Traditional Indian paper was made mainly from the recycling of paper, or from waste textiles (including gunny bags, fish nets, or rope), in addition to directly from flax, jute, and other vegetable fibers (Premchand 1995).

To overcome the non-compliant nature of such fibers, and in order to reduce the time and effort required for beating, it became common practice to soak the collected materials for many days or weeks. Potassium hydroxide (lye) or roasted lime $(\mathrm{CaO})$ was added to the fibers during the retting treatment (Hunter 1947; Anon. 1962). The extended fermentation and hydrolysis, during which the wet cellulosic material became hot (De Lalande 1761), not only softened the material, but also resulted in some loss of yield and degradation of fiber strength (Toale 1983).

Hand papermaking became associated with Gandhi's efforts to encourage India's local craft traditions, i.e. the Swadeshi movement (Soteriou 1999). According to Baker 


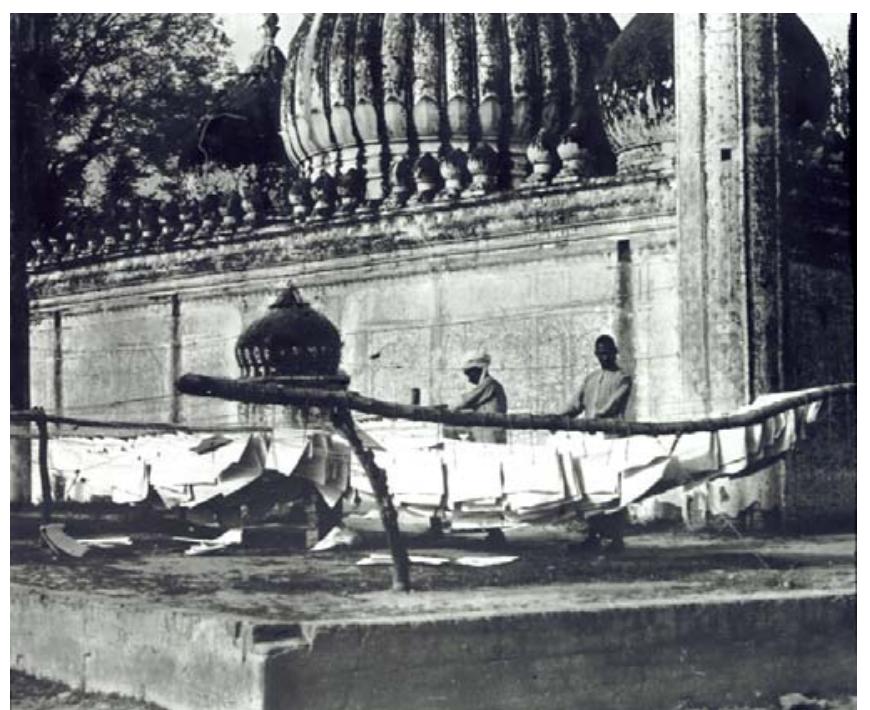

Fig. 12. Photograph of sheets drying on cow-hair ropes, taken by Dard Hunter in Sailkot, Punjab, India,from the collection of the Robert C. Williams Paper Museum).
(2000), the climax of Dard Hunter's career might be considered to be his meeting with Gandhi. The papermakers concentrated on technologies suited to implementation at the village or household scale. They employed the original Chinese style of pouring the pulp slurry onto the mold, rather than dipping (Mcfalane 1993, Koretsky 2009). This practice was well suited to the production of paper sheets having dried flower petals and other inclusions added either to the slurry or to the surfaces of freshly-formed, wet sheets.

\section{Europe}

With the spread of papermaking technology into Spain or Italy, and to the rest of Europe (Hunter 1947), an innovation occurred in the preparation and use of paper molds. Previous generations of papermakers, including those in Baghdad and Egypt, had continued to follow the Chinese tradition of preparing screens from thin reads, achieving essentially the same effect as in the case of bamboo strips. By contrast, the Europeans began to weave copper or brass wire (Hunter 1947). Rather than allowing the screen to become detached and rolled up, it was permanently fastened to the frame of the mold (Shreyer 1988). The essential design, consisting of a series of parallel filaments, woven together at intervals, was continued. As a result, the parallel "laid lines" that have been characteristic of the great majority of Asian papers also can be seen in old specimens produced in Europe. Another innovation added to the mold was the deckle. Similar in appearance to a picture frame, the deckle is placed on top of the mold during the papermaking. It aids in keeping the pulp on top of the mold and making a more uniform sheet.

European papermakers continued to employ a dipping method, following a line of tradition extending back to China. This is the same method that the Japanese have named "tame-zuki." As illustrated in Fig. 13, the papermaker typically dips the mold into a vat of fiber suspension, draws the mold toward themselves, and then turns it horizontal in a smooth motion.

The fixed-screen format necessitated a new approach to transfer of the wet sheets from the screen surface. Since the screen itself no longer could be bent or curled to transfer the sheets, the papermakers used woolen felts (Studley 1977; Kern 1980; Toale 1983). Individual sheets were first transferred to felt surfaces in a process called "couching."

Hubbe and Bowden (2009). "Handmade paper, review," BioResources 4(4), 1736-1792. 1749 

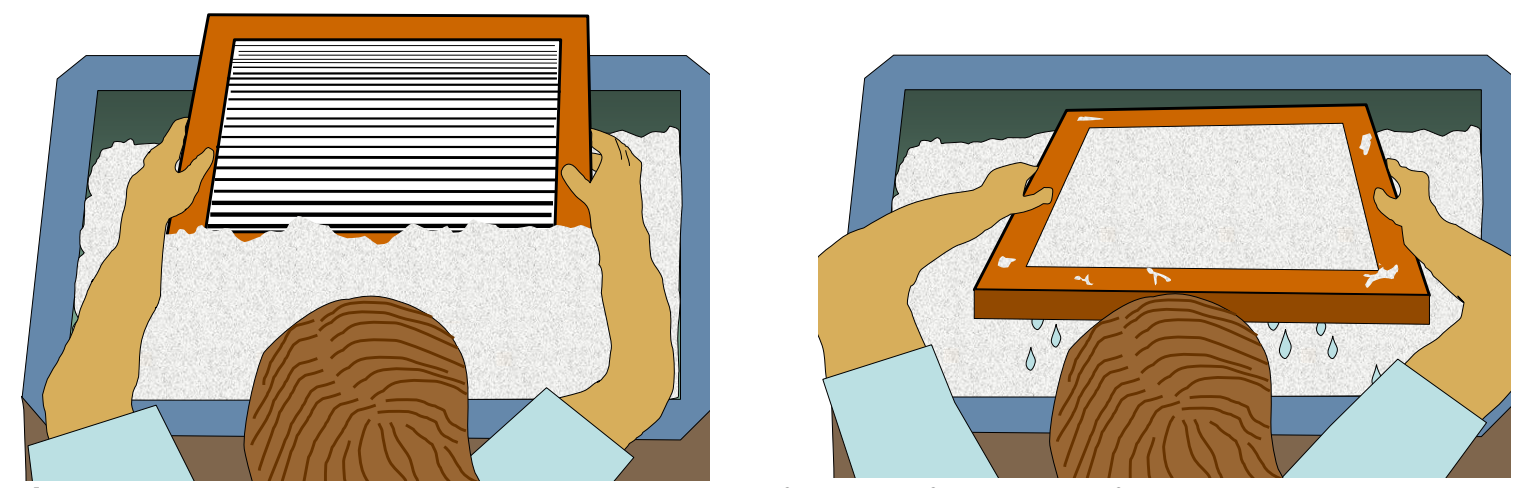

Fig. 13. Traditional hand papermaking procedure for sheet forming. Left: Papermaker is starting to dip the screen mold into a vat filled with a dilute suspension of cellulosic fibers. Right: The papermaker has drawn the mold toward herself and turned it to be horizontal, allowing the sheet to form (usually with some subtle shaking motions to achieve evenness).

By repeating this process many times, "posts" were then prepared, consisting of alternating felts and paper sheets. The posts were then squeezed at great pressure in huge screw-presses (see. Fig. 14), after which the sheets were separated and hung in lofts to dry. Great care was taken to make sure that the wet sheets were stacked exactly on top of each other. This avoided pressing creases into the paper.

European papermakers also had abundant water-power. Italian papermakers were especially successful in mechan-izing the beating of pulp (see Fig. 15), using water wheels (Shreyer 1988). As they became successful, papermaking activities practically stopped throughout the Islamic world (Bloom 2001). European papermakers mainly used rags as their fiber source (Shreyer 1988), but with the increased ability to mechanically refine the fibers, there became less incentive to follow the practice of rotting (retting) the fiber before using it.

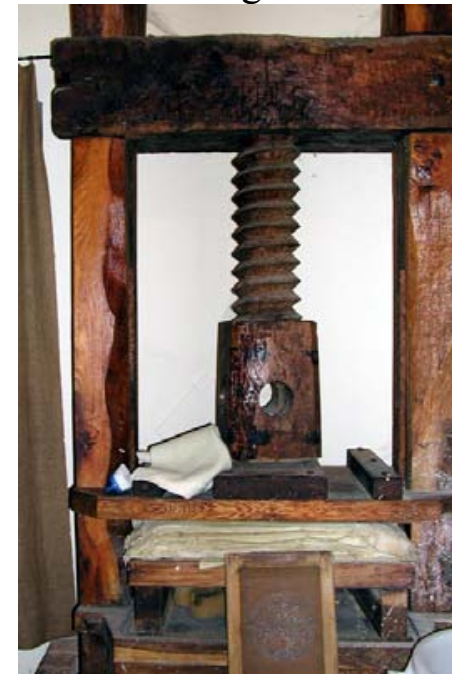

Fig. 14. Italian press from 1300s in Museo della Carta e della Filigrana, Fabriano, Italy

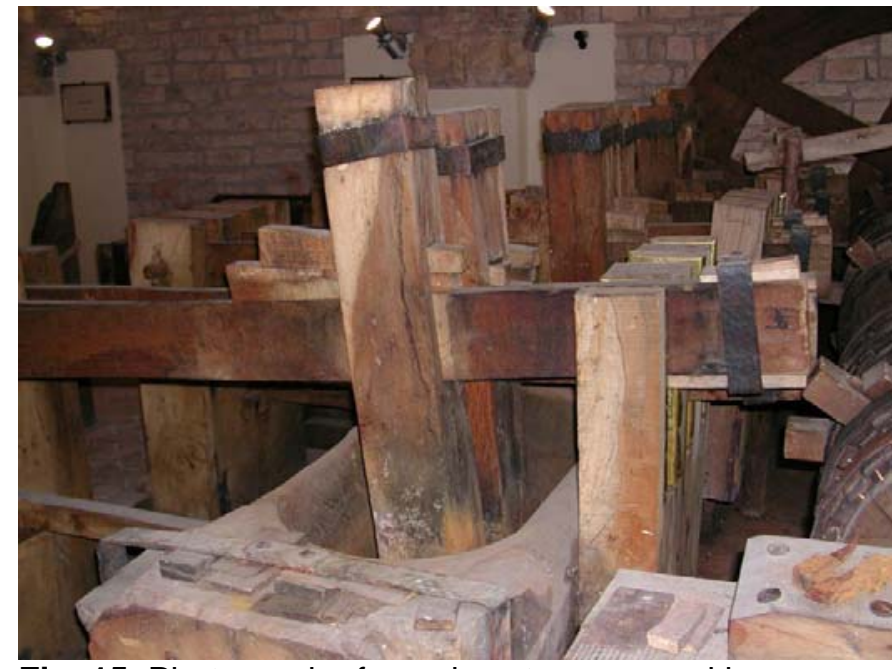

Fig. 15. Photograph of wooden stamper, working reproduction of ca. 1300 original in Museo della Carta e della Filigrana, Fabriano, Italy 
Early French papers turned a cream color due to less rinsing and to the retting of the fibers. The dependence on water power, rather than bacterial degradation to convert rags into fibers suitable for papermaking, was further stimu-lated by the development of Hollander beaters in the 1660s or early 1670s (Sturm 1718; De Lalande 1961; Hunter 1947; Heller 1978; Toale 1983; Turner and Skiöld 1983; Mcfarlane 1993).

\section{Beginnings of Modern Papermaking}

Even a review article focusing on hand papermaking traditions cannot ignore the increasing influence of the industrial revolution, which brought along with it an emphasis on science and development of increasingly sophisticated equipment. The scholarly book by De Lalande (1761), the first technical account of paper manufacturing, perhaps can be taken as a sign of changing times ahead.

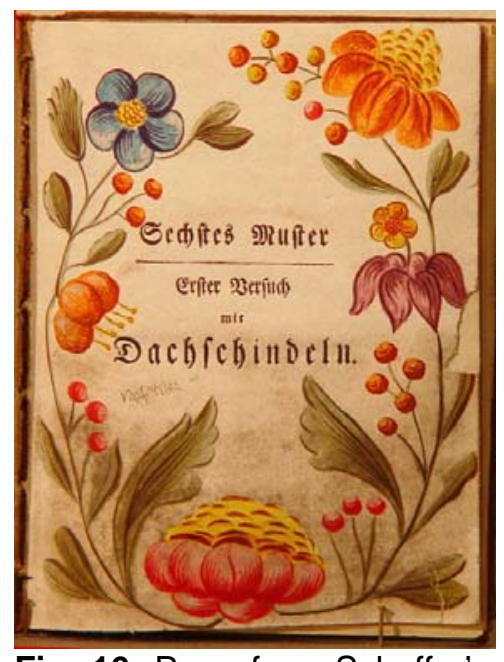

Fig. 16. Page from Schaffer's book, from the collection of the Robert C. Williams Paper Museum
Jacob Christian Schäffer, a clergyman, made a series of attempts to find alternative fibers that could be used for papermaking, due to the shortage of rags (Schäffer 1765-71, see Fig. 16; Hunter 1930). His studies were quite advanced, and he kept track of such factors as the time of harvesting of various plants and the effects of treating them with alkali solutions. Most of his paper products involved blends of cotton fibers with other kinds of fibers. His books have been researched in studies by Douglas Stone and Cindy Bowden in the translation "Papermaking Translations of the work of Jacob Christian Schaeffer," by educator Sabine Connerton. is due to be published by the Journal of the British Association of Papermaking Historians in late 2009. The work of Schaffer was continued by Mason (1963), who was more interested in aesthetics than economy, as he investigated suitable conditions of alkali treatment to release fibers from various plants that seemed interesting from the perspective of paper art projects.

The use of wood as a fiber source had been suggested already in 1719 by De Réaumur, who based his proposal on observations of wasps. He focused on certain wasps that produced especially high-quality paper-like nests (Koops 1801; Heller 1978). Matthias Koops experimented with straw and wood as fiber sources, and he wrote about other fibers that had been used in earlier times by papermakers (Koops 1801; Hunter 1930).

In 1798 Nicholas-Louis Robert invented the first paper machine capable of forming a continuous strip of paper (Hunter 1947; Heller 1978; Bloom 2001). Starting in the middle $1800 \mathrm{~s}$, with the eventual success of continuous, mechanized papermaking, the 
majority of handmade papermaking shops in Europe closed their doors. Only a small fraction of them were still operating in 1910 (Turner and Skiöld 1983; Schreyer 1988). Shreyer (1988) reports that there was a revival of interest in the late 1800s, which helped to inspire Dard Hunter and other papermakers who had an interest in history, art, or making objects by hand. This was part of the Arts and Crafts movement, a rebellion against industrialization. Hunter was a member of the Roycrofters in East Aurora, New York and worked for founders Elbert and Alice Hubbard. According to Turner (1998) during the 1920s and also during the 1960s a number of handmade paper mills sprang up either to cater to tourists, to serve as living museums, or to meet the needs of artists having discriminating needs. The more recent resurgence has been accompanied by a shift away from wood fibers and back to cotton, as well as some of the fiber types associated with early Chinese and especially Japanese papermaking (Turner 1998).

\section{TECHNICAL CHALLENGES: HOW HAND PAPERMAKERS SOLVED THEM}

The evolution of papermaking traditions has been influenced by the nature of the cellulosic fibers, their interactions with water, and behaviors that follow from their chemical composition and nanostructure. First, let us consider how traditional papermakers decided which vegetative materials to use as a source of fiber.

\section{Fiber Source Selection}

Fibers suitable for handmade paper can come from a wide range of plants, though hand papermakers have had their preferences (Hunter 1947; Tsien 1973; Turner and Skiöld 1983; Reimer-Epp 2000). Turner and Skiöld (1983) gave detailed descriptions of fibers from seed hairs (cotton, cotton linters, cotton rags), bast fibers (linen/flax, jute, hemp, kozo, gampi, mitsumata, ramie, daphne), leaf fibers (esparto, manila, grasses, giant nettle, rice straw, rattan), and wood-derived fibers (made by wasps or by pulping processes). Lorenté (2004) provides recipes for preparing the fibers from a wide and imaginative range of common plants. Tsien found evidence that some of the early papermakers in China used hemp, jute, flax, ramie, rattan, paper mulberry, mulberry, and bamboo. Present-day practitioners of traditional papermaking methods have used a very wide range of plant materials as their sources of fibers (Bell 1981, 1983).

Regardless of their source, the cellulosic fibers used by papermakers can be described as long and thin. Intact wood fibers are typically within the range of 50 to 150 times longer than they are thick. Fibers from various non-woody plant sources, such as the inner bark layers of selected plants, as well as seed hairs, such as cotton, can have an even higher aspect ratio. The slenderness of fibers is one of the key factors that makes papermaking possible, allowing each individual fiber to become bound to dozens of other fibers at their crossing points when the paper is made (Page 1969). The high aspect ratio also makes it practical to use some form of a screen to collect a thin layer of fibers from a water suspension, allowing most of the water to drain away.

What accounted for the early Chinese and Japanese preference for bast fibers such as kozo (paper mulberry), mitsumata, and gampi? And as paper spread westward, why did papermakers turn to the use of rags, rather than obtaining fibers directly from the flax

Hubbe and Bowden (2009). "Handmade paper, review," BioResources 4(4), 1736-1792. 1752 
or cotton plants? First let us consider how this selection may have been influenced by the levels of lignin in the various types of lignocellulosic material that could have been used.

\section{Low-lignin sources: bark layers, cotton}

Low lignin content was a common attribute of fibers popular among early papermakers. This certainly was true in the case of the bast fibers favored by traditional papermakers in China, Korea, and Japan (Turner 1998). Lignin would be considered to be undesirable, as a component of papermaker fibers, due to its relatively dark and unstable color, the stiff, noncompliant nature of the fibers even when wet, and its hydrophobic surface, which is not as favorable as cellulose and hemicellulose for the formation of inter-fiber bonds (Kurdin 1977).

Despite the low lignin content of traditional papermaking fibers, considerable effort still was required to remove other impurities. Procedures included steaming of kozo stems, peeling the bark, stripping colored layers away from the bark, cooking the bark in lye or lime, pounding it, and bleaching it in the sun, etc. These measures, though laborious, did not require high pressures or highly concentrated chemicals. By contrast, modern pulping methods require advanced equipment (Smook 1992; Hon and Shiraishi 2001).

\section{Bast: Kozo, gampi, mitsumata}

In choosing to work with bast fibers, early papermakers showed a preference for colorless material. The long length of bast fibers added to the attraction (Turner and Skiöld 1983). The bast fibers kozo, mitsumata, and gampi have fiber lengths in the range of about 3 to $12 \mathrm{~mm}$ (Barrett 2005). Long fibers made it possible to achieve high tensile strength and resistance to tearing, especially in the case of the thin paper sheets that were prized in Asia. The methods used to separate the fibers - treating them with mild alkaline solutions and subjecting them to mild pounding - tended to minimize any shortening of the fibers. In this respect, the traditional pounding with wooden hammers to refine fibers tends to preserve more of the fiber length in comparison to industrial refining equipment used in modern paper mills (Baker 1995).

Long fiber length added to the difficulty of forming high-quality sheets. However, entanglement could be minimized by increasing the dilution of the suspension (Kerekes and Schell 1992). In addition, traditional papermakers learned to use a mucilaginous agent (called "neri" by the Japanese), which could be obtained from the tororo-aoi plant, to minimize fiber entanglement (Barrett 2005).

Waste textiles I: The trimming of cloth

Discarded textile fibers have been a major source of fibers for the manufacture of paper. Hunter (1947) speculated that scraps left over from the trimming of textiles could have been instrumental in the invention of papermaking (Anon. 1962). Clapperton (1934) noted that occasional twisted fibers and even some woven fragments of textiles were found in some of the oldest surviving paper specimens from China, giving clear evidence of prior usage as cloth. Dynastic records agree, indicating that by the year 105 Cai Lun had used rags, along with old rope, fishing nets, hemp, and flax as some of his fiber sources (Clapperton 1934; Turner and Skiöld 1983). It has been suggested that the

Hubbe and Bowden (2009). "Handmade paper, review," BioResources 4(4), 1736-1792. 1753 
earliest papermakers mainly used rags as a fiber source, and that it was only later that they turned their attention almost exclusively to fresh vegetative sources (Bloom 2001).

Waste textiles II: Rags

Rags clearly were used as a major source of fibers when the technology spread along the Silk Road (Bloom 2001), to the Islamic world (Anon. 1962; Bloom 2001), to Europe (Blum 1934; Hunter 1947; Heller 1978; Kern 1980), and then to the United States (Weeks 1916). It would be a mistake to think that rags would be either plentiful or inexpensive relative to other possible fiber sources. While in India, Hunter (1939) expressed doubt that papermakers in that country could expect to be able to collect significant amounts of rags for fibers.

Using recycled textiles took time and energy (Heller 1978). A possible explanation for using recycled rather than virgin cotton involves the fiber length. In the process of fermenting, then heavily beating the rags, it is reasonable to expect substantial shortening of fibers, reducing the fibers' tendency to form flocs (Kerekes and Schell 1992). It is an historical irony that although fibers within trees have an almost ideal length-to-thickness ratio from the standpoint of papermaking (Hubbe 2007b), it was not until the 1800 s that suitable pulping methods were developed to make wood an attractive fiber source (Smook 1992).

\section{Fiber blends}

By blending different types of fibers, papermakers through the ages have achieved combinations of properties that they were unable to produce using only one fiber type. Often it seems that the main goal was to save money, relying mainly on an inexpensive fiber, then supplementing the recipe, as needed, with long, strong fibers suitable for reinforcement. For instance, a minor quantity of long cotton "staple" fibers can overcome a cracking tendency of paper structures made entirely from the linters, which are shorter (Heller 1978). Blending of different colored fibers has been used to achieve intermediate shades of colored paper (Turner and Skiöld 1983).

\section{Water}

Traditional papermaking operations use of large amounts of water. Even in cases where the water is recycled, the amount of water used usually far exceeds that of the fibers. It follows that the quality of water is likely to affect the quality of the paper. For example, handmade paper from Nepal may contain mica from the natural water, causing it to glitter (McFarlane 1993). To achieve clean, bright sheets it is common for papermaking villages to be situated along mountain streams, where the water is relatively clean. By contrast, water in lowland rivers and streams is expected to contain dark humic acids (Volkov and Yur'ev 1974; Hubbe 2007c), in addition to iron and manganese, all of which reduce the brightness of paper. In India, magnets have been placed in the bottoms of vats used for papermaking (Mcfarlane 1993). By collecting iron rust, the brightness of the paper was improved, and the frequency of tiny dark spots was decreased. Soft water is usually preferred for papermaking (De Lalande 1761; Birch 1964-1965). Soft water promotes the swelling of cellulosic fibers, yielding a faster response to beating, thus

Hubbe and Bowden (2009). "Handmade paper, review," BioResources 4(4), 1736-1792. 1754 
achieving increased bonding strength with less input of mechanical energy (Chen and Scott 1984; Baker 1995).

\section{A White Appearance}

Considering that paper's traditional use has been for communication with black ink, it is not surprising that there has been a strong preference for white fibers. For instance, paper mulberry fibers that were solar-bleached in shallow streams or in the snow have been described as "snowy white" (Bloom 2001). According to Bell (1981), plant fibers can be selected to give luster and transparency, in addition to great strength. Strategies that have been employed to increase paper's brightness have included mechanical separation of the fibrous material, solar bleaching, and bleaching with chemicals.

\section{Mechanical separation}

In many of the Asian countries the papermakers would peel the bark away from the stem by hand (Fig. 17). After it was rinsed, the papermakers would laboriously pick tiny pieces of bark (chiri) away from the remaining material (Bunshō 1959; Jugaku 1959; Mcfarlane 1993; Turner and Skiöld 1983; Turner 1998).

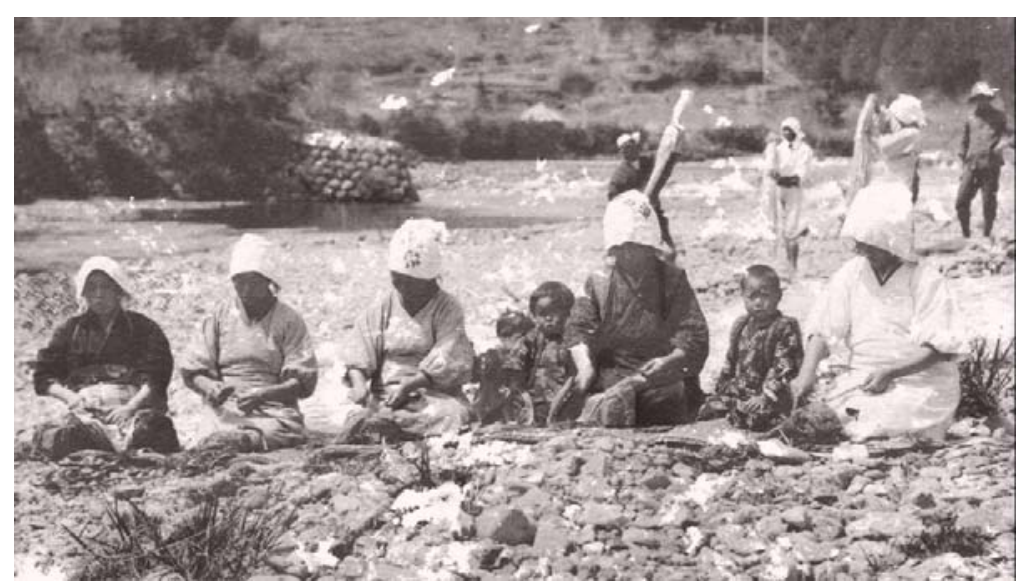

Fig. 17. Photograph of papermakers picking chiri taken by Dard Hunter in Japan, from the collection of the Robert C. Williams Paper Museum

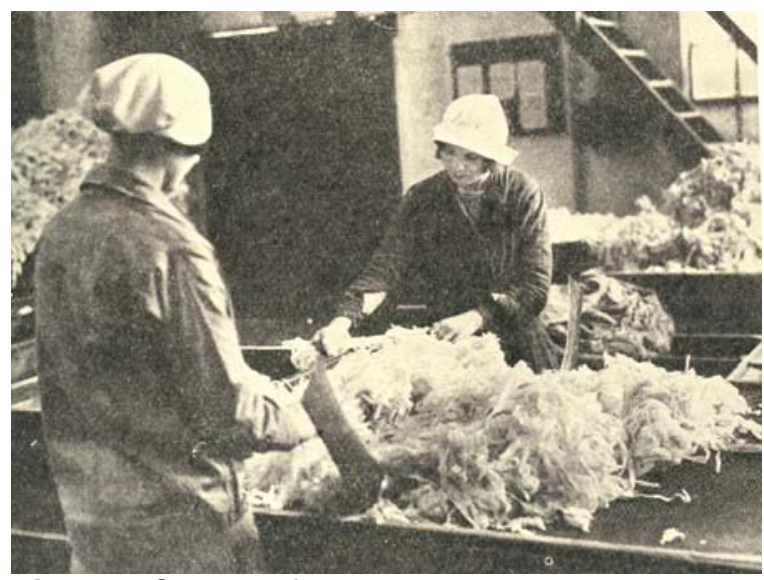

Fig. 18. Sorting of rags in Europe, ca. 1920s

Sorting continued to be one of the most time-consuming steps in the papermaking process, even when the technology reached Europe and America (Cutbush 1990. As illustrated in Fig. 18, rags were carefully sorted to separate the cotton from the linen and to take out sections that could not be cleaned, for example rust spots (De Lalande 1761; Hunter 1947). With the emergence of mechanized papermaking, it became too expensive to separate fibers according to appearance. The labor costs were high, relative to alternative approaches such as bleaching (see next). Ironically, robotic sorting of waste paper has been gaining ground in recent years (Ramasubramanian et al. 2007). The infrared reflectance and other optical attributes of paper scraps depends on their 
lignin content, along with the presence of coating layers. It is now possible to use spectral analysis to quickly identify the nature of each piece of paper as it proceeds down a conveyor belt. The paper scraps are directed into different bins by mechanical devices or puffs of air.

\section{Bleaching}

Another approach to increasing the brightness of fibers is bleaching. One of the earliest bleaching methods involved exposing the fibers to sunlight. The inner bark of paper mulberry was soaked in shallow, flowing streams, or pools made in rivers. The water helped to remove the acid from the fibers and to separate the fibers (Bunshō 1959; Toale 1983; Turner 1998). This process often required two or three days.

Bleaching became a more effective process after 1792, when chlorine was first used to treat paper pulp (Bloom 2001). Sometimes a bleaching agent was added before or during the beating operation (Hunter 1947; Cutbush 1990). Bleaching with chemicals, especially in the early years, caused pollution. Recent advances have reduced the polluting effects of pulp bleaching to very low levels by use of different oxidizing agents (McKague and Calberg 1996; Bright et al. 2000; Hewitt et al. 2006) and by effective treatment of wastewaters. Most hand papermakers today avoid the use of bleached pulps, while others incorporate bleaching as a routine practice (Lorenté 2004).

\section{Separating the Fibers (Pulping and Beating)}

Pulping is the act of separating a lignocellulosic material into its component fibers. Beating (or "refining") is the application of mechanical action to separate the fibers. In mechanical pulping processes, mechanical energy is used both to separate the fibers from each other and to impart a suitable amount of flexibility to the fibers so that they can be formed into a sheet of suitable uniformity and strength. At the other extreme, chemical pulping operations require much less subsequent application of mechanical energy to separate the fibers, since the chemicals attack the natural binding agent. A modern kraft pulping process can be optimized to degrade, solubilize, and then remove essentially all of the lignin from a wood chip, so only mild force is needed to disperse them into their component fibers (Smook 1992). Between these the extremes, represented by pure mechanical pulping of wood, vs. kraft pulping, hand papermakers have achieved different balances between chemical and mechanical treatments, which together result in the conversion of materials into fibers.

\section{Lignin removal with alkali}

Alkaline treatments have been used since ancient times for the pulping of lignocellulosic materials (Hunter 1947; Bunshō 1959; Mason 1963; Takeo Co. 1979; Bell 1981; Toale 1983; Turner and Skiöld 1983; Mcfarlane 1993; Premchand 1995; Plowman 1997; Turner 1998; Potter 1999; Barrett 2005). Clapperton (1934) was among the first to note that papermakers used soaking in alkaline solutions to minimize the time of beating required to develop the needed degree of inter-fiber bonding.

In the earliest times it is likely that the alkaline solution was prepared mainly from ashes. For instance, in Japan it was common to prepare dilute solutions rich in $\mathrm{KOH}$ by first burning straw or reeds, then using water to leach the alkali from the ashes (Hughes 
1978; Barrett 2005). This type of solution was gentle in comparison to the strongly alkaline solutions used in modern pulping operations (Hon and Shiraishi 2001). Even with soaking times of an hour or more, the strength of the fibers tended to be preserved (Barrett 2005). In India they used lime powder for the soaking (retting) of hemp before it was used for papermaking (Anon. 1962; Mcfarlane 1993; Bloom 2001). In addition, an impure form of sodium carbonate was obtained from burning certain plant material (Hunter 1939). Even bamboo can be retted in pools of sodium carbonate solution, as long as one is willing to wait many months for the process to be completed; a similar effect can be achieved in several days if the solution is boiled (Koretsky 2009). Hand papermakers in Europe treated rags with alkaline solutions to aid in their conversion to tractable fibers for papermaking (Clapperton 1934; Hunter 1947). The use of $\mathrm{NaOH}$ makes it feasible to use fibers from an almost limitless range of plant materials, as long as one followed suitable cooking recipes; in many cases one to two hours of boiling in a $10 \%$ caustic solution is enough to release the fibers from each other (Lorenté 2004).

\section{Rotting and fermenting}

Another way to prepare fibers to come apart more easily is to let them rot (or be retted). This technique was widely used in regions where rags were the main source of fiber (De Lalande 1761; Anon. 1962; Soteriou 1999). The fermented fibers responded quickly to mechanical refining (see below). Sorted piles of rags were washed and then kept wet for up to 6 weeks (De Lalande 1761; Hunter 1947; Kern 1980; Toale 1983). Sometimes lime was added to speed up this retting process (De Lalande 1761). The retting of fibers reduced the strength and yield of fibers from a given amount of rags (Anon. 1962). As paper production grew in Europe, the shortage of rags became critical, and it became increasingly important to avoid loss of material. To maintain a high yield, modern hand-papermakers generally skip the retting step, tear rags into small pieces, and use high-quality refining equipment (Hamady 1982).

\section{Beating or refining of pulp fibers}

Papermakers from almost all traditions have applied some kind of pounding or shearing action to the wet fibers either as part of the pulping process (i.e. "mechanical pulping") or after the fibers have been freed from each other as a result of cooking with alkaline solutions. The effectiveness of pounding or shearing masses of cellulosic fibers can be attributed to their layered nature. As a result of this structure, repeated compression or shearing tends to cause delamination within the fiber walls, and the fiber surfaces can become fibrillated. The tubular or somewhat rectangular cross-section of many cellulosic fibers tends to become flattened as a result of beating, and the resulting ribbon-like shape and increased conformability of the beaten fibers allows for greater bonded area, leading to higher strength of the paper (Page 1969).

\section{Asian beating of pulp with mortar and pestle}

The traditional beating of pulp fibers in China and most of Asia has used human power, either by means of a mallet (Fig. 17) or by repeatedly lifting and dropping a heavy rod. The rod was dropped endwise into a mortar that contained a relatively high-solids fiber suspension (Toale 1983; McFarlane 1993; Turner 1998). As noted by Turner, the 
fibers were prepared with a suitable amount of water so that they could be pressed into balls before the beating operation. This tradition was continued as paper technology made its way to India (Mcfarlane 1993). Traditional beating of pulp was sufficiently gentle for delamination to occur mainly within the fiber walls. Delamination makes the fibers more flexibile when wet, allowing them to conform to each other more closely and form stronger inter-fiber bonds. Traditional

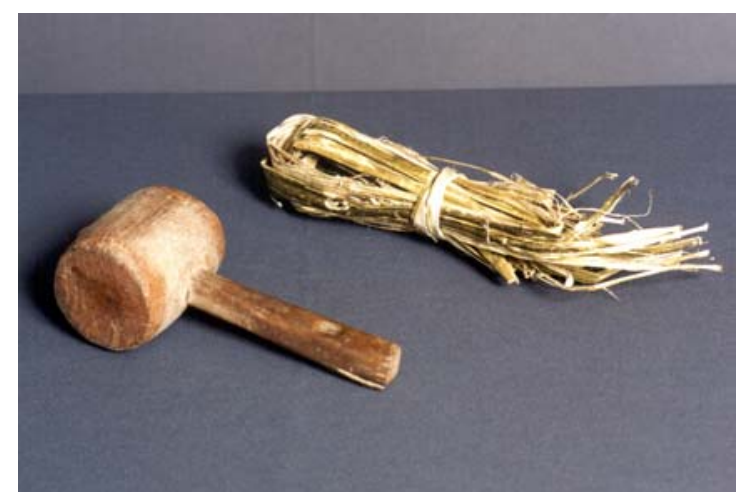

Fig. 19. Pulp beater and kozo fibers, c, 1920, Japan, from the collection of the Robert C. Williams Paper Museum

beating practices generally do not cause much external fibrillation or damage to the fibers (Turner and Skiöld 1983).

Heavy beating (stampers), to undo the spinning of fibers

Once papermakers began to use cloth as a main source of fibers, there was an incentive to find a more forceful and less tiring way to separate the fibers. This was achieved mainly with "stampers," which are devices with wooden triphammers (Soteriou 1999), which are repeatedly lifted and dropped by means of water power (De Lalande 1761; Anon. 1962; Toale 1983; Turner and Skiöld 1983; Cutbush 1990; Bloom 2001) or foot power (Premchand 1995; Koretsky 2009). Figure 20 shows an example. There also are records of the early use of stampers in China (Clapperton 1934). The effect on the fibers would, at least in principle, have been the same as when the refining energy was applied by hand.

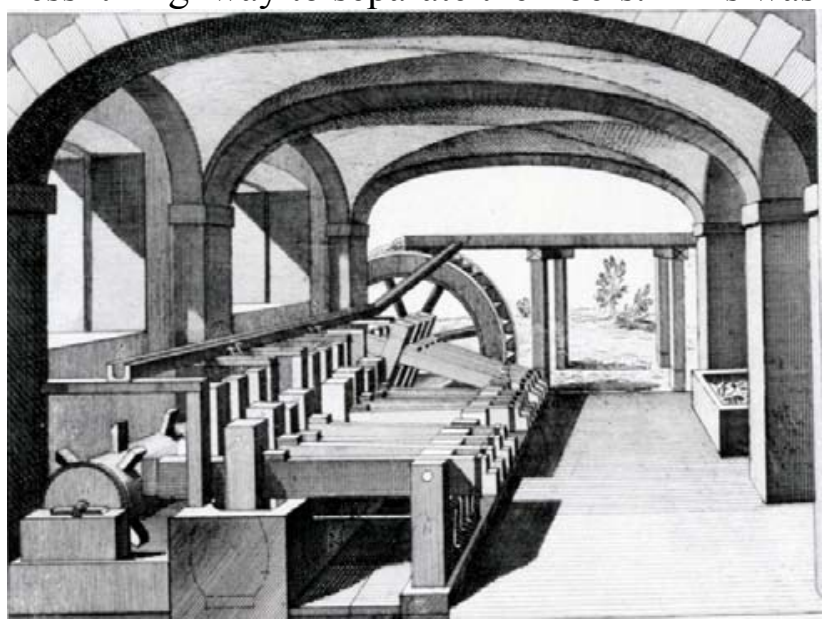

Fig. 20. Drawing of stampers from the Diderot Encyclopedia, France, 1798, from the collection of the Robert C. Williams Paper Museum

\section{The Hollander beater}

Stamping mills remained the dominant means of refining fiber until well after the development of Hollander beaters during 1660-1673 (Sturm 1718; De Lalande 1761; Heller 1978). Hollander beaters were designed to work well with wind power. Figure 21 shows both a laboratory-scale beater and a set of industrial-scale beaters. Pulp is circulated in the beater so that it passes repeatedly between a large rotating roll with metal rectangular blades rubbing against a bed-plate (Hunter 1947; Anon. 1962; Toale 1983; Turner 1998). As Hollander beaters became a preferred method of refining rag pulp, fermentation procedures were no longer required (Hunter 1947; Cutbush 1990). In modern times, even though large-scale mechanized papermakers who use wood-derived 
fibers have largely abandoned Hollander beaters in favor of yet more energy-sparing devices, Hollanders continue to be held in high regard by serious hand-papermakers (Barrett 2005).
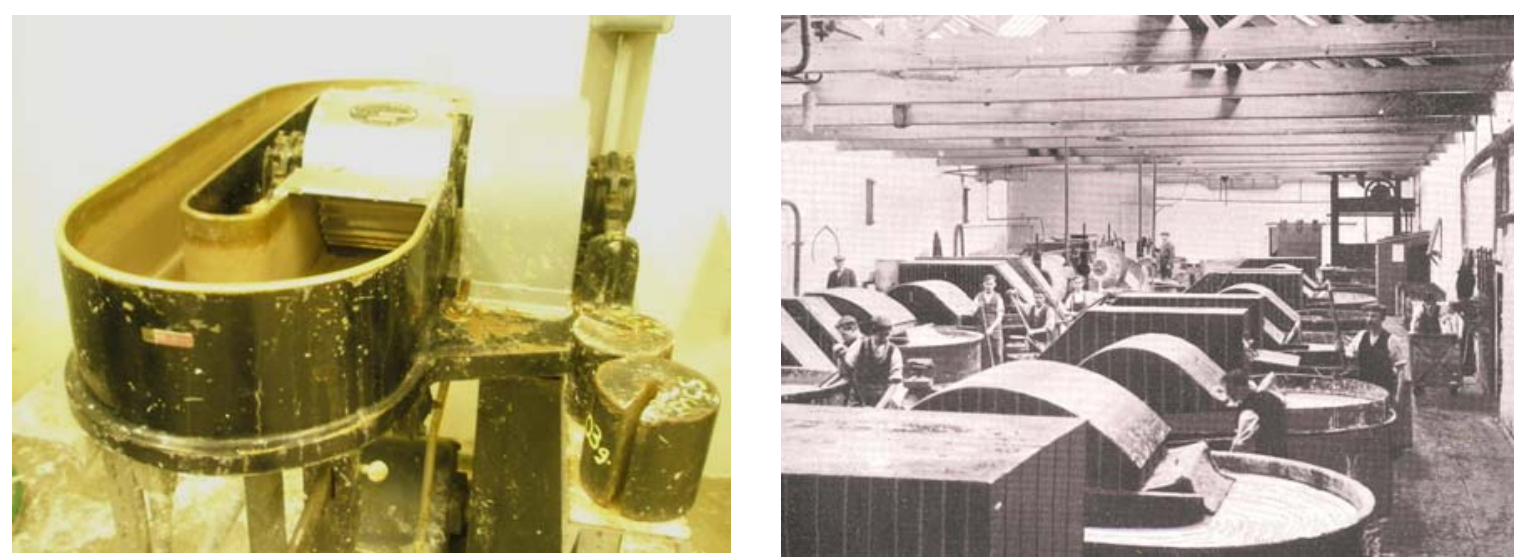

Fig. 21. Hollander beaters. Left: Laboratory-scale beater by Valley Machinery Co. (North Carolina State University); Right: Industrial-scale beaters (photo from Robert C. Williams American Museum of Papermaking)

Hollander beaters use less energy to impart a given level of bonding ability to papermaking fibers, compared to stamping mills or hand-beating. The mode of action on the fibers is quite different. In a stamping mill, as well as in hand beating processes, the beating action repeatedly compresses the fibers. By contrast, the Hollander beater imposes a greater degree of shearing at the fiber surfaces. Because cellulosic fibers are composed of wound layers of fibrils (Duschesne and Daniel 1999; Courschene et al. 2006), shearing causes external delamination of the fibers, resulting in fibrillation of the surface and detachment of fibrillar fines. Recent research has shown that gentle fibrillation of fiber surfaces may be a preferred strategy to preserve the integrity of fibers, making it possible to recycle them more times (Somboon et al. 2009). By contrast, internal fibrillation essentially "uses up" the fiber's bonding ability, and the fibers are subsequently not as suitable for preparing strong recycled paper.

Many traditional users of Hollander beaters have employed "washing drums," devices designed to remove some of the water during the refining process. The drum is a screen-covered cylinder with its axel positioned so that the drum dips into the fiber suspension. The flowing pulp within the beater causes the drum to rotate. Filtrate flows by gravity into the interior of the drum, from where it can be removed. Traditional papermakers could use these devices either to increase the consistency of the refined fiber suspension or to wash the pulp by successively diluting with fresh water and then removing filtrate.

In relatively modern times refining equipment called the naginata, which looks outwardly similar to the Hollander beater, has become popular among Japanese traditional papermakers. Where the Western form of the beater has rectangular bars rubbing against a bed-plate, the Eastern version has claw-like elements on its rotor and no bedplate (Heibert 2000; Koretsky 2009). The action of the latter version is believed to be more gentle, serving mainly to separate and to remove knots from the pulp. 


\section{Chemical Additives to the Fiber Slurry}

There have been widely divergent practices with respect to adding substances other than cellulosic fibers to the slurry before the sheet is formed. On the one hand, papermakers have appreciated the fact that cellulosic fibers are in a sense self-sufficient; after beating, the fibers can be formed into strong paper even without the use of any chemical additives. On the other hand, additives may be used for product differentiation, changing such attributes as brightness, smoothness, or strength.

\section{Dyeing and mordants}

Traditional papermakers occasionally have added colorants to the fiber slurry. Most often these colorants were natural plant materials added to the fiber slurry before the paper was made. One of the main challenges has been to transfer the colored material efficiently from the water onto the fibers permanently. Heller (1978) lists a wide variety of mordants that have been used in efforts to increase the firmness and efficiency with which the colorants stay on the fibers. The list of mordants includes salt, vinegar, sodium carbonate, cream of tartar, brass, iron, tin, copper, alum, and tannic acid. From this list most papermakers will recognize alum (e.g. aluminum sulfate) as an effective mordant for dyes. The strong positive charge of aluminum-containing ions attaches the negatively charged fiber surfaces and the colorants, many of which also would be expected to behave as weak acids. In other words, they develop a negative charge when in water having an intermediate or high $\mathrm{pH}$.

\section{Minerals}

The use of mineral fillers for papermaking started to make sense as paper began increasingly to be used for writing on both sides of the sheet. The size of clay or finely ground limestone particles is well suited to the scattering of visible light, thus increasing paper's opacity. Clapperton (1934) noted that filled papers were being produced in the Islamic world.

\section{Water resistance}

Adding a chemical to the fiber slurry so that the resulting paper would resist water apparently was not implemented until relatively recent times. Starting in the early 1800 s, papermakers began to use rosin in combination with aluminum sulfate, an acidic chemical, to impart hydrophobicity to paper, i.e. for "internal sizing" (Kern 1980; Cutbush 1990). An unfortunate side effect of such practices is a more rapid degradation of the paper's strength and resistance to folding during storage. Thus, many paper products made after the early 1800 s tend to become brittle at rates much faster in comparison to much older books and manuscripts that were prepared without the use of alum (Barrow 1974; McComb and Williams 1981; Barrett 1989). Problems with embrittlement, due to the use of alum, even have affected some Japanese handmade papers (Barrett 2005).

There are two ways to explain the negative effects of alum and acidity on paper's ability to fold without cracking. The simpler explanation is that acidic conditions, especially when accompanied by high relative humidity during storage, tend to favor more rapid acid hydrolysis of glycosidic linkages within cellulose molecules (Arney and 
Chapdelaine 1981; Klungness and Caulfield 1982; Welf et al. 2005). Thus, acid hydrolysis reduces the molecular mass of the cellulose and weakens the material. The other reason is that when paper is formed and dried under acidic conditions, with the acidic groups in their uncharged form, the fibers lose much of their ability to swell when placed back into water (Lindström and Carlsson 1982). By contrast, fibers dried under neutral or alkaline conditions, a practice followed by most papermakers throughout the ages, tend to retain their ability to swell again, allowing them to regain their flexibility and bonding ability.

Fortunately, there has been a major shift in sizing practices within the modern paper industry, especially during the 1980s through the 1990s (Hubbe 2005). Presently most paper intended for printing, writing, or artwork, whether it is made by hand or on a machine, is made under neutral or slightly alkaline $\mathrm{pH}$ conditions, and concerns about premature embrittlement have been considerably reduced.

Turner and Skiöld (1983) provide some useful ideas for modern hand papermakers who would like to explore different strategies for making their products more water-resistant. Mechanisms governing such "internal sizing" of paper recently have been reviewed (Hubbe 2007a).

\section{Strengthening and debonding}

Given the prominent role of strength-enhancing chemicals in the preparation of machine-made paper, surprisingly little has been published regarding the use of drystrength additives in handmade paper. The dry-strength chemicals most often used by industrial papermakers are cationic polymers, a class of materials that became available only in the mid-1900s. Mcfarlane (1993) noted that Islamic papermakers sometimes added cooked starch to the vat in order to strengthen paper. Recent research has shown that the adsorption efficiency of unmodified starch onto paper fibers can be very inefficient in comparison to that of cationic starch (Roberts et al. 1987).

It would be a mistake to assume that every papermaker is trying to maximize strength. For instance, papermakers sometimes want to produce limp paper, which can be achieved by adding linseed oil or similar materials to the fiber slurry before the sheet is formed (Kern 1980).

\section{Forming the Sheet}

The high length-to-thickness ratio of typical papermaking fibers has certainly played a role in the evolution of traditional papermaking practices. On the one hand, the length of papermaking fibers makes it possible to collect them efficiently on a screen. But a high aspect ratio also presents a challenge with respect to achieving a uniform appearance of the paper. Papermaking fibers in a suspension have a strong tendency to form bunches of fibers called flocs, due to random collisions and entanglements. Fortunately, hand papermakers generally have been able to avoid an excessive level of flocculation in their products by working with sufficiently dilute slurries. The maximum practical solids level of a papermaking slurry often can be estimated based on the lengthto-thickness ratio (Kerekes and Schell 1992). 


\section{Dipping method: Tame-zuki sheet-forming}

Papermaking can be defined as a process using fibers, water, and some type of sieving action. Several approaches have been used by traditional papermakers to form the

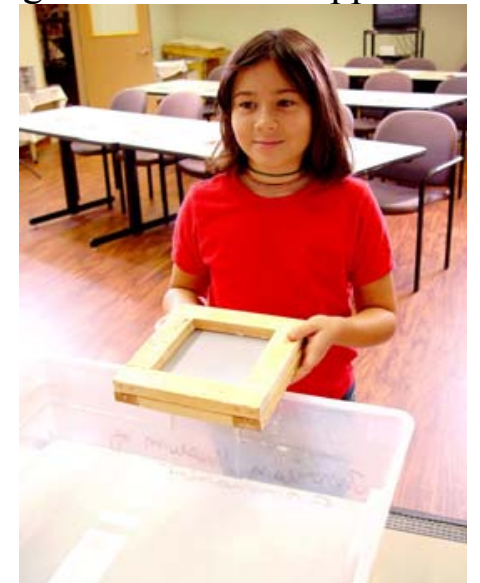

Fig. 22. Participant in the Robert $C$. Williams Paper Museum's educational programs for children. sheet. The approach used by far the majority of papermakers goes by the Japanese term tamezuki (Clapperton 1934; Hunter 1947; Premchand 1995) (Fig. 22). This entails stirring the fiber suspension in a vat, dipping a screen into the vat, and then forming the sheet. In the Western tradition, the papermaker starts by holding a deckle, which looks like a picture frame, against the top of the mold. Starting with the mold and deckle held almost vertical or at a 45-degree angle, the papermaker dips it a few inches into the vat, while drawing it forward and smoothly turning it to a horizontal position and letting the water start to drain (Hunter 1947; Heller 1978; Takeo Co. 1979).

\section{Pouring method}

There are many accounts of traditional papermakers who have used an alternative "pouring" method to form paper. Papermakers who use this approached usually pour the fiber slurry within the perimeter of a screen that is floating on the water. The wooden frame defines the dimensions of the sheet (Mcfarlane 1993; Premchand 1995; Soteriou 1999; Bloom 2001; Yang et al. 2005; Koretsky 2009).

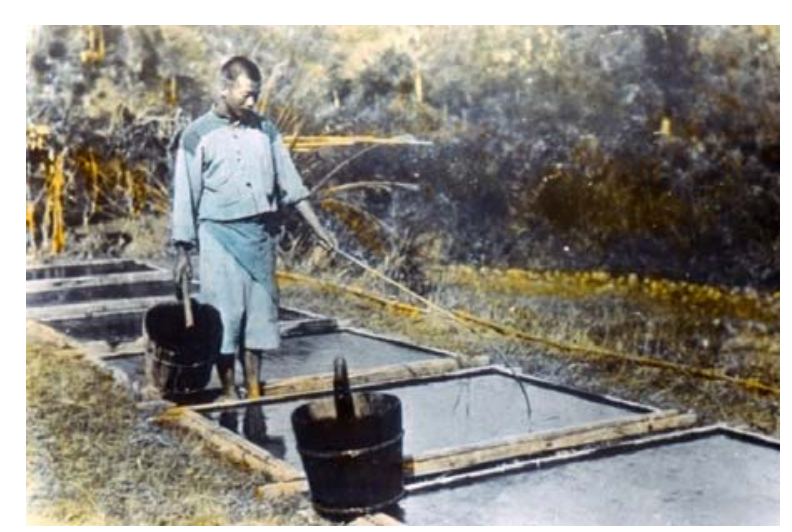

Fig. 23. Pouring fiber onto the papermolds floating on water, ca. 1920, China

The fibers are distributed evenly across the mold by swirling the pulp with the hands or with a very coarse comb. Then the screen screen is raised to drain the water, and it is placed in the sunshine to dry with the sheet still attached (Mcfarlane 1993; Premchand 1995; Koretsky 2009). Though the practice is less common, it is also possible to pour fiber slurry containing a high concentration of formation aid onto the surface of a dry mold, suspended in air (Koretsky 2009); in such cases, the papermaker has to quickly tilt the mold surface as needed to distribute the slurry as evenly as possible over the screen surface. 


\section{Shaking}

Many papermakers have achieved better results if, almost immediately after lifting the mold from the vat, they apply small, quick back-and-forth shaking motions (Hunter 1947; Kern 1980; Turner and Skiöld 1983; Mcfarlane 1993; Plowman 1997). Heller (1978) suggested that the shaking motions, especially when they were directed first front-to-back, and then side-to-side, arose from the papermakers' desire to influence the orientation of fibers in the paper. Fibers tend to align themselves in the direction of flow (Stover et al. 1992; Orts et al. 1995; Ulmar and Norman 1997). The mark of a master papermaker is that they have perfected their shaking method or "stroke," always keeping an eye on how their dipping and shaking actions affect the quality of the product (Glanville and Thomas 1990).

Needless to say, forming sheets can be quite tiring, especially very large sheets. Benjamin Franklin, who was ever curious about inventions that could help in his printing businesses, was impressed by the counter-weight systems used in some Chinese operations to compensate for the weight of the mold (Heller 1978). Such devices were also used in Japan, India, and Iran at various times (Turner 1998; Bloom 2001). Today, papermakers take care to stand correctly at the vat and work on how to hold the mold and deckles. Many use a similar counterweight system to prevent injury.

\section{Nagashi-zuki sheet-forming}

One of the most fascinating ways to form paper is the Japanese nagashi-zuki method (Hughes 1978; Leitner 2005). Often washi (Japanese handmade paper) is made with several layers, building one on top of the others. The molds (sugetas) are made from bamboo woven together with horse hair. The fibers are usually from kozo (mulberry trees), mitsumata, or gampi. The fibers are mixed with water and suspended in the water with the aid of neri (from tororo-aoi root, a hibiscus plant).

To form a sheet, the papermaker dips the sugeta into the vat and swishes the fibers and water back and forth across the screen in waves (see Fig. 24) (Hunter 1947; Bunshō 1959; Hughes 1978; Turner and Skiöld 1983; Barrett 2005; Pietzcker 2009). Often the papermaker starts by drawing the mold toward them, while placing an edge of it deep enough into the vat to pick up just enough slurry to make an initial thin layer of paper (Turner and Skiöld 1983). The papermaker then continues to let waves of pulp pass either front-to-back or side-to-side across the screen several times. Layers of fiber gradually build up on top of the already-formed layers, until the derived weight has been deposited on the screen. Finally, any excess slurry can be flipped off of one end of the screen when the wave reaches that point. By attention to detail, the ply construction can be optimized to achieve great smoothness and strength (Hori 1991).

A key factor that can enable a nagashi-zuki papermaker to form high-quality paper, even when using very long fibers, is the presence of mucilage in the water (Hunter 1947; Bunshō 1959; Jugaku 1959; Hughes 1978; Bell 1981; Toale 1983; Turner and Skiöld 1983; Hori 1991; Turner 1998; Barrett 2005). Known in Japan as "neri," the mucilage is obtained from the tororo-aoi plant. The roots of this plant are cleaned and hung to dry. The roots are smashed and either filtered or placed in a cloth bag, which is placed in the water to be used for papermaking, following the principle of a tea-bag. 
According to Premchand (1995), although papermakers in India sometimes added mucilage to the fiber slurry, they often spread the mucilage to the sheet surface (see later discussion of "sizing"). Due to its water-loving, polymeric nature, the mucilage contributes to inter-fiber bonding (Hubbe 2006). The addition of mucilage also results in a more uniform sheet, and both factors can increase the strength of the paper. Similarly, gelatin (Plowman 1997) or starch (Kern 1980) can be added to the fiber slurry to increase the strength of handmade paper. Addition of a high level of mucilage also can make the

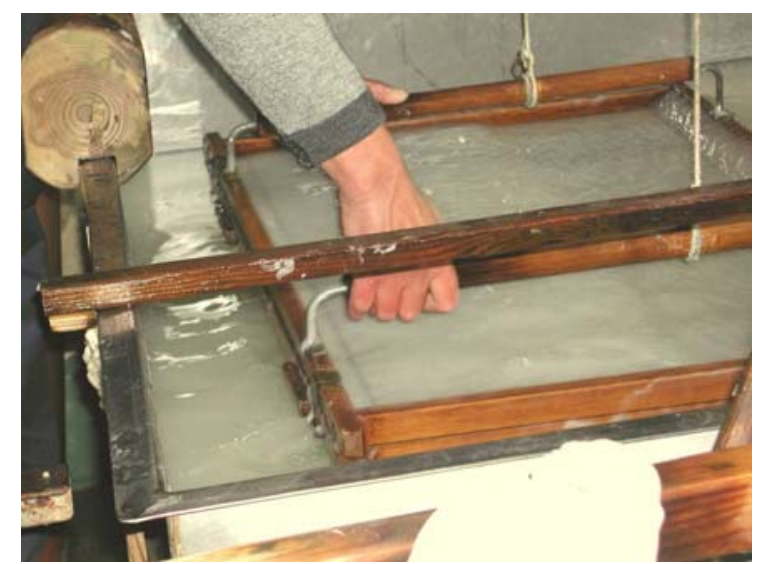

Fig. 24. Demonstration of nagashi-zuki paper forming method. Note wave moving from left to right. National Treasure Iwano Ichebei in Imadate Japan pulling a sheet, 2001 paper glossy (Turner and Skiöld 1983).

Two mechanisms have been proposed to make clear how the mucilage minimizes fiber entanglement and slows the rate of drainage through the screen. First, the presence of very-high-mass, water-loving macromolecules in the solution phase greatly increases the extensional viscosity (Lee and Lindström 1989). This effect keeps the fibers in suspension from rubbing against each other. Whenever two fibers are forced towards each other, the intervening macromolecules become squeezed, and they keep the fibers apart, allowing them to slide past each other. The second explanation assumes that some of the mucilage is adsorbed onto the fibers; forcing two fibers toward each other causes deformation of the adsorbed layers of macromolecules (Zauscher and Klingenberg 2001; Lee and Lindström 1989). Again, the result is that the fiber surfaces easily slide past each other. Though it is not clear which mechanism is the more important, mucilaginous materials can be very effective deflocculants, as long as the added amounts are sufficient and sufficient time has been allowed so the material can completely mix with the suspension (Wasser 1978; Lee and Lindström 1989; Yan et al. 2006).

\section{The forming screen}

Much attention has been paid by papermakers to the design and construction of the paper mold and deckle. The simplest and possibly the earliest way to construct a mold was weaving a mesh cloth and attach it to a frame made from bamboo or other wood (Hunter 1939, 1947; Anon. 1962; Mcfarlane 1993). A similar approach reappeared much later in Europe, where the printer John Baskerville used James Whatman's newly developed wove paper to produce his famous edition of Virgil in 1757 (Heller 1978; Turner and Skiöld 1983).

The most common form of mold used throughout Asia, in the Islamic world, and even after the technology had spread through much of Europe, employed screens that have featured prominent monofilaments aligned in one direction, i.e. the "laid" mold (Hunter 1947; Mcfarlane 1993; Turner 1998; Soteriou 1999). Most of the earliest paper samples show clear evidence of having been formed with such screens (Clapperton 1934; Hunter 1947). In Asia, these were often made from bamboo or from carefully selected 
reeds having a round cross-section. When making such molds from grass stems, the small end of one stem was inserted into the large end of the next, thus forming filaments of arbitrary length (McFarlane 1993). Silk threads, animal hair, or other types of threads were then woven at intervals in order to hold the grass or bamboo filaments as an even mat, with relatively uniform spacing (Anon. 1962). Indeed, the subtle patterns formed by such threads (in India called "chapri lines" and sometimes called "chain lines") have been used by historians to differentiate handmade papers from different sources (Clapperton 1934; Mcfarlane 1993). The basic concept of using parallel filaments, woven together at intervals by much thinner filaments, persisted even after the Moors in Spain started to use wires (Anon. 1962) in place of the traditional vegetative matter (grasses, bamboo, etc.) that had been used continuously since the invention of paper about a millennium earlier.

Various explanations can be offered as to why the traditional laid design of molds remained dominant, despite the fact that it generally resulted in a characteristic marking of the paper surface with parallel lines. Part of the reason may be the relatively easy release of the formed paper sheet from smooth, parallel filaments, in comparison to peeling a wet sheet of paper from a woven screen with multifilament threads. Fibers tend to build up on the equipment over time, even obstructing flow through the screen if not cleaned. Multi-filament threads are more difficult to keep clean, in comparison to the smooth surfaces of reeds or slender cylindrical bamboo strips. Clapperton (1934) speculated that the relative coarseness of traditional laid screens used in Asia was well suited to the rather long bast fibers that were being used there.

Another great advantage of the traditional laid screen is that, when it was used with a detachable frame (Turner 1998), it could be rolled up. More will be said about this in a later section dealing with the transfer of wet sheets onto other surfaces.

\section{The deckle}

Papermakers have used different approaches to constraining the pulp suspension when making the sheet. The word "deckle" refers to a wooden frame placed over the top of a removable laid screen (Anon. 1962; Kern 1980), or which surrounds the top of the permanently-mounted screen in the case of traditional European molds (Hunter 1947; Anon. 1962; Plowman 1997; Turner 1998). Korean papermakers used a pair of deckle sticks to hold the screen against the lower frame of the mold as they formed each sheet. In Cambodia, Laos, Vietnam, Malasia, Myanmar, Singapore, Thailand, and parts of China paper has been formed without using sticks or frame above the level of the screen (Hunter 1947; Koretsky 2009). In such cases the frame below the screen defines the edges of the sheet, since appreciable drainage, and the resulting sheet formation will occur only through parts of the screen that are unobstructed.

A consequence of forming a sheet by hand is that the edge of the sheet, i.e. the "deckle edge," tends to be rough. The rough edge is a consequence of the random arrangement of fibers at the edge of the sheet. Since papermaking fibers are generally $1 \mathrm{~mm}$ or more in length, the fuzziness of the sheet's edge can be quite visible. Early papermakers usually cut off the edges, considering them to be an imperfection (Hunter 1947; Premchand 1995). Handmade paper today has achieved more prestige, and papermakers often retain the deckle edge. The concept of a deckle also has been 
extended in a new direction, using shaped deckles to form individually shaped pieces of paper (Plowman 1997).

\section{Watermarks}

A watermarked sheet of paper bears some kind of lettering or design that becomes readily visible only when the sheet is held up to the light. The use of watermarks came into being only after papermaking had become well established in Europe (Hunter 1947; Kern 1980; Turner and Skiöld 1983). The earliest watermarks were made in Italy in the $12^{\text {th }}$ century (Shreyer 1988). The first known watermark formed a figure " 8 " and was developed by the Fabriano papermill in Fabriano, Italy. The mill produced the first Italian paper with sizing. All of the other mills claimed that their paper had sizing as well, and the Fabriano mill needed an identification mark. As more mills began to copy the watermark, Fabriano began changing the design. Series of watermarks were developed featuring water jugs, oil pots, and even dancing cows. A key element in this innovation was the fact that the Europeans used metal wires in the construction of their molds. The traditional way to prepare such a watermark involved the fashioning of a relatively simple design of letters from wire (Plowman 1997), then attaching the bent wires to the surface of the mold either with finer wire (Hunter 1947) or by soldering.

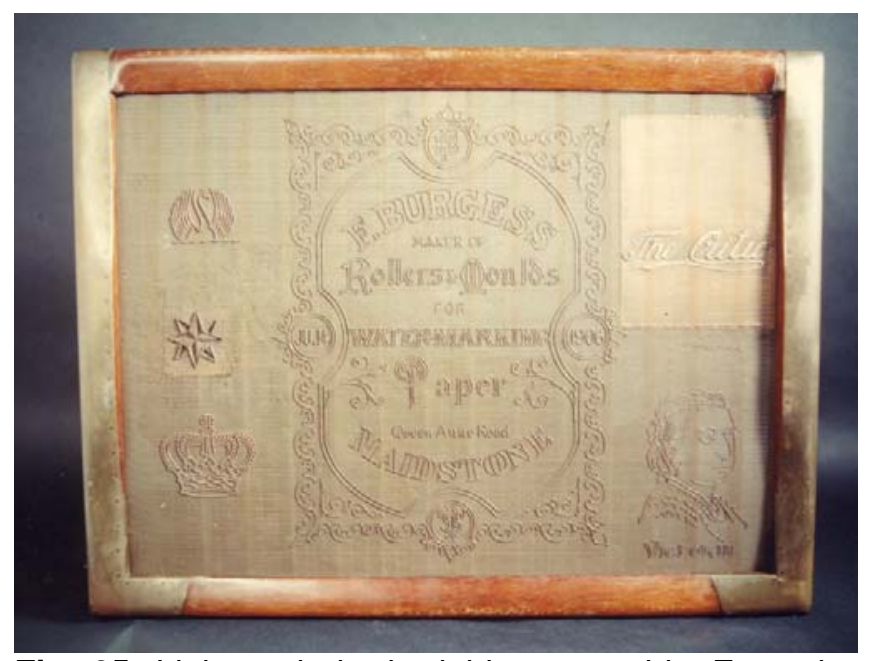

Fig. 25. Light and shade, laid papermold. From the collection of the Robert C. Williams Paper Museum
Figure 25 shows an example of a handsheet mold prepared for making watermarked paper. When a sheet of paper is formed, the thickness is reduced wherever a wire rests on top of the screen, and the contrast between these thin areas and the surrounding paper can be seen when viewing the paper against a beam of light (Heller 1978). As watermarks grew in popularity, they were used to identify the manufacturer or for supplying the client with personalized paper (Blum 1934; Anon. 1962; Bloom 2001). For instance, both Benjamin Franklin (see Fig. 25, left) and George Washington had their own watermarked writing paper (Anon. 1962).

Watermarking is also used for various artistic purposes (Potter 1999.) One of the most advanced and delicate forms of watermarks is the light-and-shade watermark, i.e. "chiaroscuro." Such watermarks are achieved by carefully manipulating the surface of a metal screen. To make the watermark, the artist starts by carving into a thin slab of wax while it is backlit. By paying close attention to reproducing the shaded appearance of the drawing, the artist achieves a seemingly exaggerated topography, as required for the watermarking process. Once the carving process has been completed, the wax is brushed with an electrically conductive powder and electroplated with copper to a thickness of about 2-3 millimeters. The wax is removed, and then the thin copper shell is reinforced 
by filling it with lead. The die prepared in the described manner is then used to prepare its mate, using a similar method. This is a time consuming process, sometimes taking up to 3 months. The artist's name on the watermark is the person who carved the wax. If a mistake is made in the carving process, the artist must start over. The finished dies are pressed on either side of the brass or copper screen of the paper mold (Hunter 1947; Heller 1978; Turner and Skiöld 1983). During sheetmaking, the parts of the screen that are higher than the surrounding areas tend to receive a thinner layer of fibers, and viceversa. The resulting watermarks, when well executed, can have a photo-like quality. The right-hand frame of Figure 26 shows an example of a light-and-shade mold, designed to create both thicker and thinner areas in the formed sheets.
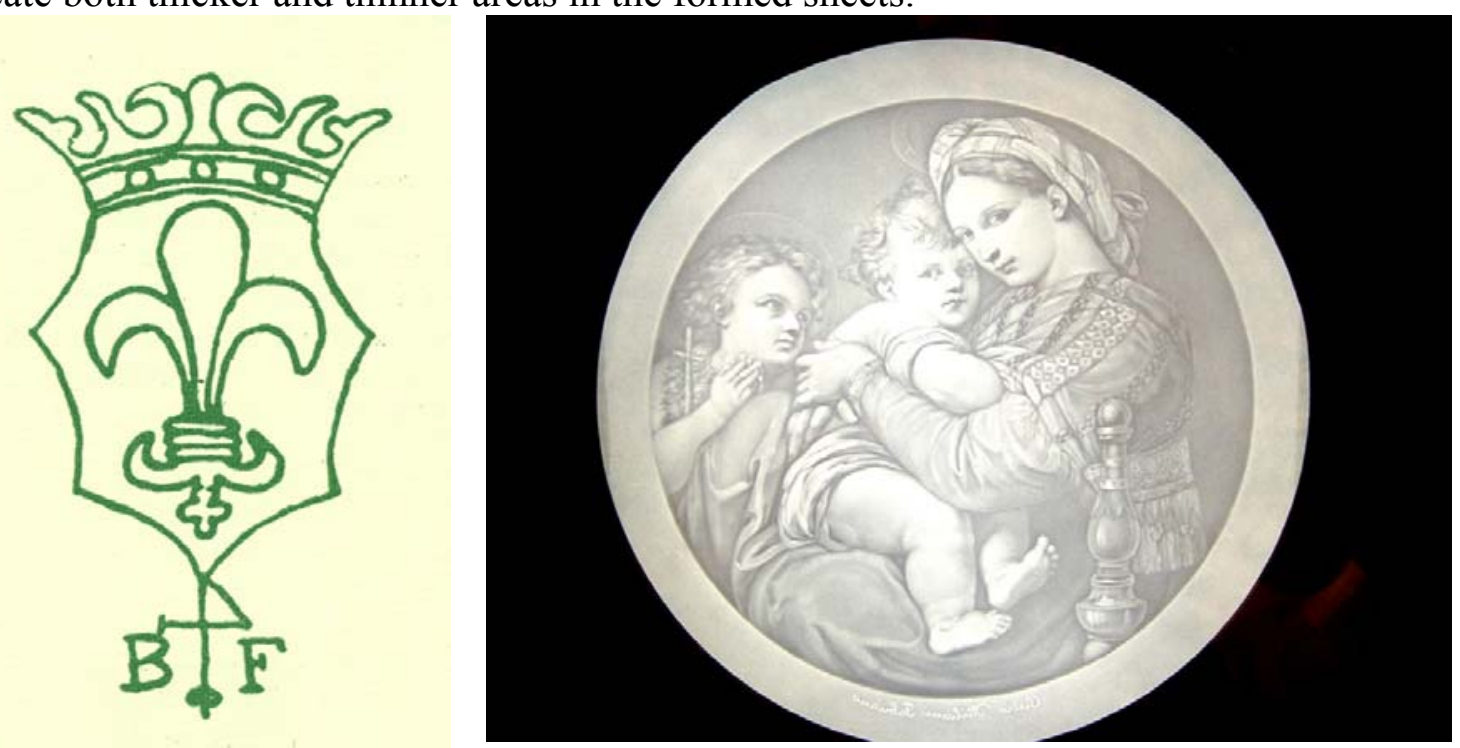

Fig. 26. Watermarks. Left: Benjamin Franklin's watermark. Right: Light and shade watermark, Fabirano Italy, ca. 1950. Both from the collection of the Robert C. Williams Paper Museum

\section{Removing the Water}

In comparison to forming a sheet, the subsequent drainage of water is anticlimactic. In Europe a practice developed where the mold, with its freshly-formed sheet, was placed on a slanted surface, which helped water to run off from the bottom side of the screen (Hunter 1947). By dividing the job of papermaking between the papermaker (vatman) and a coucher, there was a time interval during transfer, allowing more water to drain from the paper. The vatman detached the deckle from the mold and immediately used it again to form the next sheet with a second mold.

Factors affecting the rate of release of water from paper during its formation were considered in recent review articles (Hubbe and Heitmann 2007; Hubbe et al. 2009). Clearly the viscosity of the water is a primary factor. The practice of heating the vat (Hunter 1947; Turner and Skiöld 1983), though it would have increased the comfort of the papermakers, was probably done to speed up the dewatering process and increase the production rate. 


\section{Couching: Transferring the Wet Paper to a Stack}

When a papermaker uses only a single mold, each new sheet must be removed before making the next sheet. This is an inherently delicate operation, given the very weak nature of a wet sheet of paper, especially before pressing. Before paper has been dried, capillary forces are the main contributor of strength to the sheet (Campbell 1959). Wet, unpressed paper is characterized by a very low tensile strength to breakage, but a relatively high tolerance for stretching before it breaks (Seth et al. 1984). However, uncontrolled stretching of wet paper should be avoided, since it is likely to result in later problems with curling and puckering of the paper in response to changes in humidity (Corte and Herdman 1975).

\section{Couching from a rigid mold}

Different strategies for transferring the wet sheet have been employed, depending on whether or not the sheet is detachable from the lower frame of the mold. In the case of a rigidly attached screen, as used in Europe, transfer was achieved by means of felts (Hunter 1947; Anon. 1962; Heller 1978; Hamady 1982). When picking up the mold, from which water still is draining, the coucher immediately flips the mold so that the wet sheet faces downward, and the whole assembly is placed with a smooth gentle rocking motion onto the surface of a dampened felt. Hamady (1982) recommended lining up and squeezing one edge of the sheet against the felt, then using a rolling motion, pressing the whole sheet down firmly against the felt. The mold is then gently lifted away, taking care not to touch the vulnerable surface of the wet paper. The transfer can be expected to become easier after a pile of alternating sheets and felts has been built up enough to become curved on its surface. By using a fixed number of felts, it was easy to keep track of the number of sheets in a set (Cutbush 1990).

\section{Couching from a flexible laid screen}

A different approach is used in the case of paper that had been formed on detachable laid screens, i.e. "su" or "sugeta" (Clapperton 1934; Hunter 1947; Anon. 1962; Longenecker 1985; Yang et al. 2005; Kortesky 2009). In Asia a single papermaker did both the forming and the couching. The first step was to detach the screen from the frame. Then, by slightly curling the screen, the papermaker positions one edge of it onto a stack of previously formed sheets. The screen is then gently uncurled in such a way as to avoid capturing any bubbles or wrinkles between the adjacent sheets (Hunter 1947). Because of the much finer texture of the paper, compared to the screen, the screen can be then removed, with relatively little tendency for the sheet to want to stay on its surface.

\section{Pressing}

Because of the water-swollen nature of papermaking fibers - especially after they have been beaten - it is usually not sufficient just to remove water by gravity or suction. Rather, most traditional papermaking methods include pressing of the wet sheets before they are dried. Quite different traditional methods of pressing the paper were established in the East and in the West, though it is reasonable to expect that there was a great deal of variation within each tradition. 


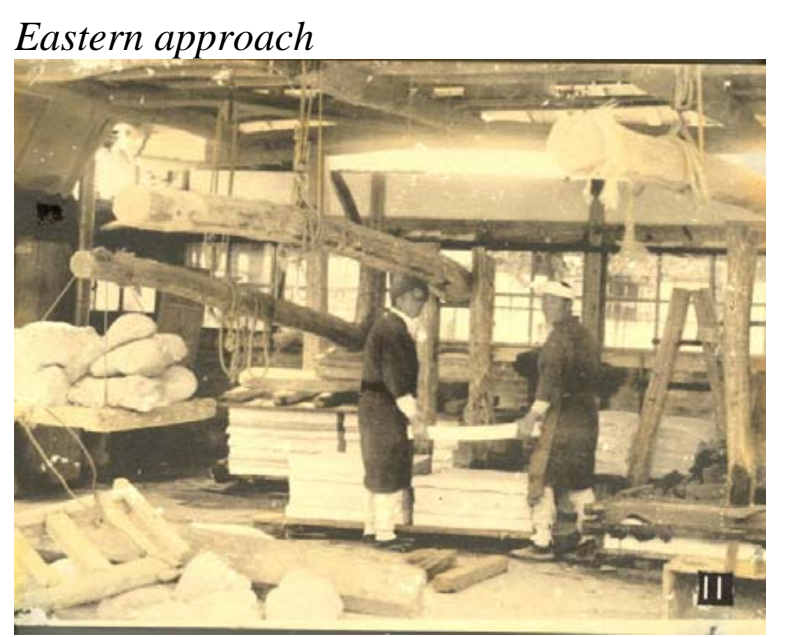

Fig. 27. Pressing the paper in Kochi Japan, photo taken by Dard Hunter, is in the collection of the Robert C. Williams Paper Museum
According to the Eastern tradition, the papermakers deposited wet sheets directly on top of each other, forming a "post." This was pressed at moderate pressure. The pressure was raised gradually, often by adding weights little by little to a lever arrangement, as illustrated in Fig. 27. The loaded press was usually left over night, providing a long time for the water to make its way among and through the sheets of paper (Bunshō 1959; Toale 1983; Turner and Skiöld 1983; Turner 1998). As a variation on this practice, sometimes textured cloth sheets were

interposed between the new paper sheets in order to impart fancy patterns (Premchand 1995).

The separation of sheets after pressing can be one of the most critical steps during the preparation of paper, using the traditional Eastern approach (Hughes 1978). One well could ask how it is even possible to separate individual sheets that have been pressed together while still wet. Indeed, sometimes it is not possible. If the sheets have not been pressed enough, they may remain too wet, and therefore won't have enough strength to be handled individually. On the other hand, too high a pressure sometimes has been found to convert a post of paper into a very thick piece of inseparable cardboard. The mucilage used in the preparation of paper by the nagashi-zuki method is believed to help in the release of paper from the post after pressing. But the layered nature of nagashizuki paper can make it tricky to initiate the separation between, rather than within sheets of pressed paper. To get around this problem, papermakers sometimes insert a piece of straw under the corner of each sheet as it is sheet as it is laid onto the post.

\section{Western approach}

When papermakers began to use rigid screens, possibly in Persia in the $8^{\text {th }}$ century (Turner and Skiöld 1983), they started to employ numerous felts, enough so that one sheet of woolen felt could be placed between each sheet of wet paper in the post. Because the felts offered spaces for water to flow, it was then possible to apply great pressure, using screw presses (Hunter 1947; Kern 1980; Toale 1983; Plowman 1997; Turner 1998).

Because the felts tended to mark the surface of the sheets, it was customary to follow up the first pressing with a second pressing, during which the paper sheets were carefully lined up on top of each other, but with no intervening felts (Kern 1980; Turner and Skiöld 1983; Turner 1998). Sometimes this was done multiple times, repositioning the sheets between each pressing. Hamady (1982) noted that the secondary pressing operations should not be as intense as the first pressing, presumably because no felts would be present to support the sheets and to accommodate water pressed out of them. 


\section{Nip pressing}

Although the approach has been relatively little used by traditional papermakers, pressing in a nip between rollers represents another viable option (Heller 1978). One can readily understand, however, why this approach never became popular among handmade papermakers. The nip pressing operation at low speed can be expected to impart distortion to the sheet in the direction of passage through the nip.

\section{Transfer to a Smooth Surface for Drying}

The peeling of wet sheets from a post

Another transfer is needed, according to most papermaking practices, before the paper can be dried. This transfer step is most critical in the case of paper sheets formed according to the eastern tradition, since they still can contain as much as $80 \%$ water by mass even after overnight pressing (Turner and Skiöld 1983). Problems could be expected if the paper remained too wet after pressing, but also if too much water was removed by pressing (Longenecker 1985). An excessively wet sheet would not have sufficient tensile strength to withstand the forces during transfer. Conversely, a sheet with insufficient water would not stick to a smooth wooden surface (see section on drying). As shown by Seth et al. (1984), the tensile modulus of a wet sheet of paper increases with decreasing moisture content as paper is pressed to different extents. There are three reasons to expect that typical paper sheets formed according to the western tradition were more easily transferred from the post after pressing: Their solids content tended to be higher, due to the high pressures applied in screw-press operations, noting that the felts between the sheets provided a place for the pressed water to flow. The dry mass per unit area of a typical western sheet tended to be higher, since paper was usually meant to be printed on both sides of the sheet. And finally, the relatively coarse pore structure of the felts, in comparison to the paper, tended to yield a lower capillary force, compared to the force of adhesion between adjacent wet sheets of paper in a post formed according to the eastern tradition.

Due to the manner in which they are formed, nagashi-zuki sheets can be susceptible to delamination during peeling or transfer steps (Barrett 2005). This is a reasonable consequence of the ply construction of such paper, which results from the way fibers are deposited from waves of fibrous suspension traversing the screen surface, often in different directions from the preceding layer of fibers. To overcome such effects, increased pressure can be used when sheets are pressed over night, thus increasing the cohesion within the paper. The mucilage used in forming nagashi-zuki sheets also aids in the separation of wet sheets from the post.

\section{Porous, smooth nature of the support}

Some of the preferred surfaces that papermakers in different places and at different times have used for the drying of paper have included smooth, unvarnished wood (Jugaku 1959; Hughes 1978; Turner 1998) and plaster walls (Hunter 1939; Mcfarlane 1993; Koretsky 2009). In addition to their smoothness, such surfaces are inherently porous. As illustrated in Fig. 28, some of the moisture from the paper immediately wicks into the support material, and a substantial capillary force that develops as a consequence of this wicking can be expected to help hold the paper on the

Hubbe and Bowden (2009). "Handmade paper, review," BioResources 4(4), 1736-1792. 1770 
surface. The transfer step, in traditional papermaking, is achieved by gently peeling a wet sheet from the top of the post and using a wide, soft brush to gently press it against the surface to be used for drying (Jugaku 1959; Premchand 1995).
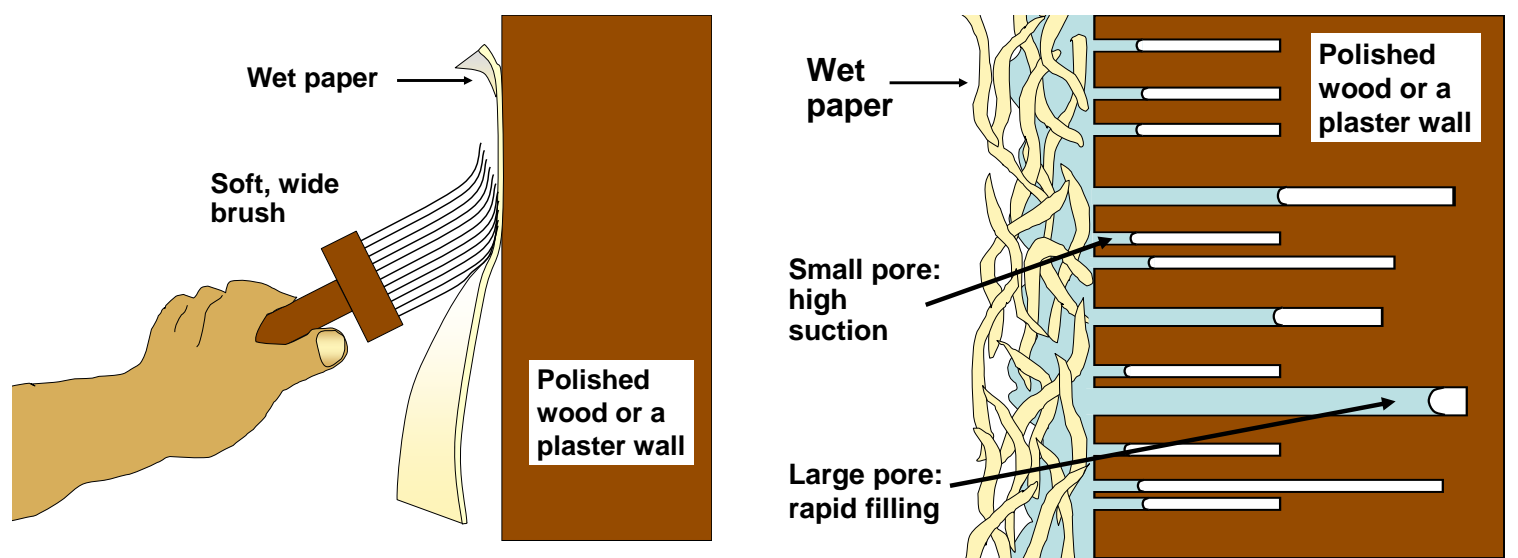

Fig. 28. Transfer of wet paper sheet to smooth, porous surface (polished wood or plaster) for drying. Left: Application with a brush. Right: Capillary suction provided by relatively large pores (potentially more rapid flow) and small pores (potentially higher vacuum).

On theoretical grounds one can expect that the best practical effects might be achieved if there is a mixture of differently sized pores in the wood surface. Relatively small pores have the potential to generate higher differential pressure. The maximum strength of capillary suction can be estimated from

$$
\Delta P=2 \gamma_{\mathrm{LV}} \cos \theta / R
$$

where $\gamma_{L V}$ is the interfacial tension, $\theta$ is the contact angle (drawn through the water phase), and $R$ is the radius of the capillary (modeled as an ideal cylinder) (Lyne and Huang 1993). Meanwhile, the distance $L$ that liquid of viscosity $\eta$ is drawn into a capillary during time equal to $t$ can be estimated from the Lucas Washburn equation (Hoyland and Field 1976):

$$
L=\left[2 R \gamma_{L V} \cos \theta t /(4 \eta)\right]^{1 / 2}
$$

It follows that at least initially, before a substantial suction develops, the most rapid uptake of water will involve the larger pores.

Another factor that can help out in transferring the sheet is the smoothness of the receiving surface. Modern papermakers have found that a web of wet paper will tend to follow the smoother of two surfaces, for instance when a sheet is between a roll and a felt at the exit of a nip (Fekete and Waugh 1981). Again, the effect is consistent with what would be expected for capillary forces. It is just more difficult to achieve good capillary suction between a sheet of paper and a rough surface. The effect can be enhanced, during transfer of handmade papers, by applying a thin film of water; thus, pre-wetted glass has been used to receive very thin sheets of handmade paper (Heller 1978). 


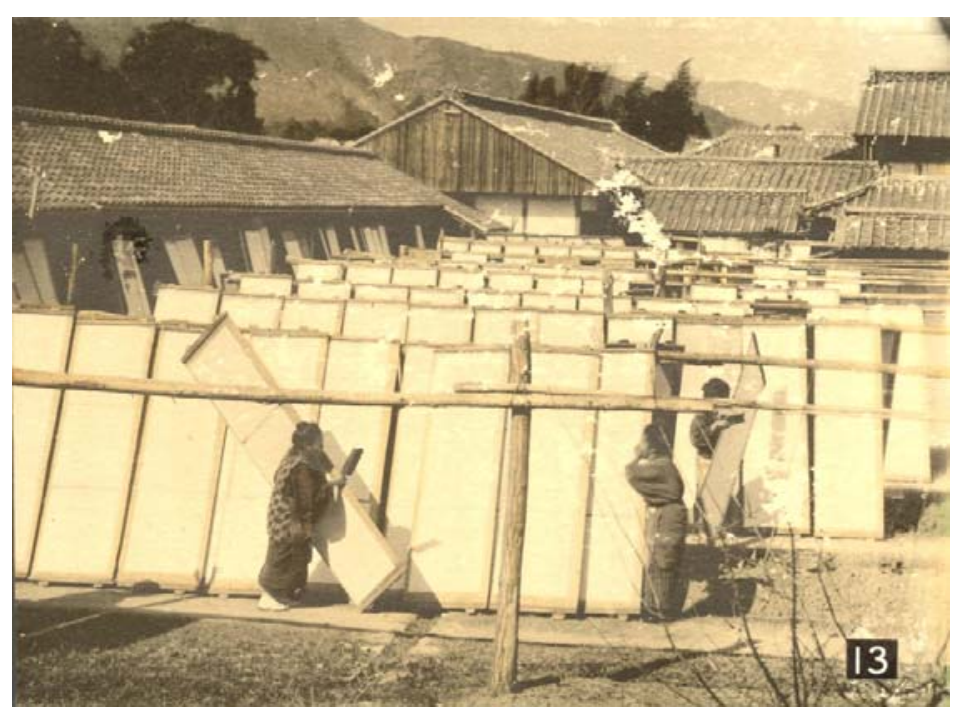

Fig. 29. Drying sheets on boards in the sun, 1933, photo by Dard Hunter in Japan, part of the Robert C. Williams Paper Museum collection
In addition to smoothness on at least one side of the dried paper, procedures in which paper is dried against a surface also can profoundly affect the paper's dimensional stability. When paper is dried without restraint, relative size of the sheet can shrink by several percentage points, and the effect tends to become more severe as the level of refining of the fibers increases (Corte and Herdman 1975).

Cellulosic fibers, especially those from which lignin has been removed, have a natural tendency to shrink when they are dried. Most of the shrinkage occurs in the thickness direction, and the width of a fiber can be reduced by several percent as a result of drying. Much of the shrinkage can be attributed to an effect of capillary pressure, which favors the closing up of pores within the fiber structure as the water evaporates (Campbell 1959; Stone and Scallan 1966; Weise and Paulapuro 1998). Because the cellulose molecular chains within the dominant layers of a fiber a generally oriented in their length-wise direction, an individual fiber, dried by itself, will suffer very little lengthwise shrinkage. However, a fascinating process can occur when the fibers are formed into a sheet of paper and dried in contact with each other. In that case, the shrinkage of one fiber in its cross direction can cause crimping at the crossing point of an adjacent fiber, which effectively shortens the second fiber (Page and Tydeman 1962; Gallay 1973; Uesaka and Qi 1994). This process, when repeated innumerable times, can cause a general shrinkage of the whole sheet, except if the planar dimensions are somehow constrained during drying. If the sheet is constrained just by its edges during drying, there can be a complex "tug-of-war" between thicker parts of the sheets and thinner parts of the sheet, resulting in an amplification of differences in local basis weight. By contrast, paper that is dried against a surface remains completely fixed in its planar dimensions, so it remains undistorted and flat during drying.

\section{Use of solar energy or steam}

By placing the wooden boards out in the sunlight, or also by selecting walls facing the sun, traditional papermakers have taken advantage of solar energy to dry the paper (Bunshō 1959; Jugaku 1959; Turner and Skiöld 1983; Mcfarlane 1993; Premchand 1995; Turner 1998). Once the paper is dried, the capillary forces cease to function, and the paper either can be easily peeled away, or in many cases it falls off by itself. In cases where release of the dried paper is difficult, it has been recommended to pre-treat such surfaces with talcum powder (Potter 1999). 
But papermakers who depend on the sun can face problems in times of cloudy or rainy weather. Thus steam-heated metal surfaces are sometimes used in Japan (Jugaku 1959; Longenecker 1985). A related approach has been used by some modern papermakers, often taking advantage of the kind of equipment used to dry traditional photographic prints. For such purposes Heller (1978) recommends a drying temperature no higher than $90{ }^{\circ} \mathrm{C}$, presumably to avoid scorching the paper.

\section{Hanging of Paper Sheets to Dry}

A completely different approach to the drying of paper became common in Europe: hanging the paper in lofts (De Lalande 1761; Hunter 1947; Mcfalane 1993; Premchand 1995; Turner 1998). The most common approach was to drape the sheets over ropes. The attic spaces above the papermaking factories were considered to be most suitable for drying, and it was usual to open windows or vents to maximize air flow, depending on the weather.

Hunter (1947) warns against efforts at speeding up the drying process, a warning that probably stems from various problems, such as wrinkles, that can result from uneven drying. In order to minimize wrinkling it was customary to dry "spurs" consisting of about 4-10 sheets still pressed together (Hunter 1947; Turner 1998). In addition to slowing down the drying process, it is reasonable to expect that the multiple layers of paper in a spur increased the thickness of the structure enough to overcome susceptibility of an individual sheet to change its shape in response to uneven stresses during drying.

In cases where serious wrinkles were present in the final sheet, papermakers generally would put the scraps back into water, mix thoroughly, and then use the pulp as part of the composition of new sheets. In fact, such practices probably have been common in papermaking operations for much longer than the word "recycling" has been used. Another, less drastic approach to remove relatively small wrinkles involves spraying the sheet with water and then drying it again (Kern 1980). The latter approach takes advantage of the fact the cellulosic fibers swell when they are wetted and contract during drying, except that the degree of contraction can be constrained if the paper is held tightly against a flat surface as it is dried (Corte and Herdman 1975).

\section{Surface Treatments (sizing)}

The two most common reasons for which papermakers apply liquid solutions to the surface of dry sheets are to increase the strength and to make the surfaces more suitable for writing (Cushing 1979). Such "surface sizing" treatments most often have been carried out with solutions of either gelatin (Hunter 1947; Kern 1980; Toale 1983; Turner and Skiöld 1983; Barrett 1992; Barrett and Mosier 1995) or starch (Clapperton 1934; Kern 1980; Turner and Skiöld 1983; Schreyer 1988; Mcfarlane 1993). A paste of fish glue was sometimes used in China (Premchand 1995). The solution can be applied to the paper either by dipping the sheets into the solution or by passing the sheets through a wetted press-nip between rollers (Turner 1998).

The effects of applying starch or gelatin solutions to the paper surface possibly can best be explained by a mechanism involving partial film formation (Jansson and Jarnström 2005; Kjellgren and Engström 2008). A partial film is consistent with a pronounced decrease in the air-permeability, which is typically observed when paper is

Hubbe and Bowden (2009). "Handmade paper, review," BioResources 4(4), 1736-1792. 1773 
surface-sized. The strengthening effects due to surface sizing can benefit from the fact that the applied polymer will tend to have its greatest strengthening effect near to the top and bottom surfaces of the sheet. By increasing the elastic modulus of the paper in the layers nearest to the outside of the sheet, the effect on stiffness is maximized.

\section{Smoothing and Polishing}

Dried paper can be described as viscoelastic. The term implies that the paper will not return to exactly its original form after it has been strongly compressed, stretched, or bent. A sufficiently intense force, especially when it is accompanied by local frictional heating, can cause the lignocellulosic material to flow. Papermakers from many traditional have taken advantage of this fact, especially when they have wanted to achieve a smooth surface.

\section{Rubbing with a stone}

When papermakers in ancient times wanted to achieve a polished effect, they usually rubbed the paper surface with a smooth stone or shell (Mason 1963; Kern 1980; Turner and Skiöld 1983; Mcfarlane 1993; Premchand 1995; Turner 1998; Soteriou 1999). The paper was often backed by a concave, smooth wooden surface during polishing (Premchand 1995). Agate and flint stones were often used in Europe, and these stones sometimes were embedded in clay for easier handling.

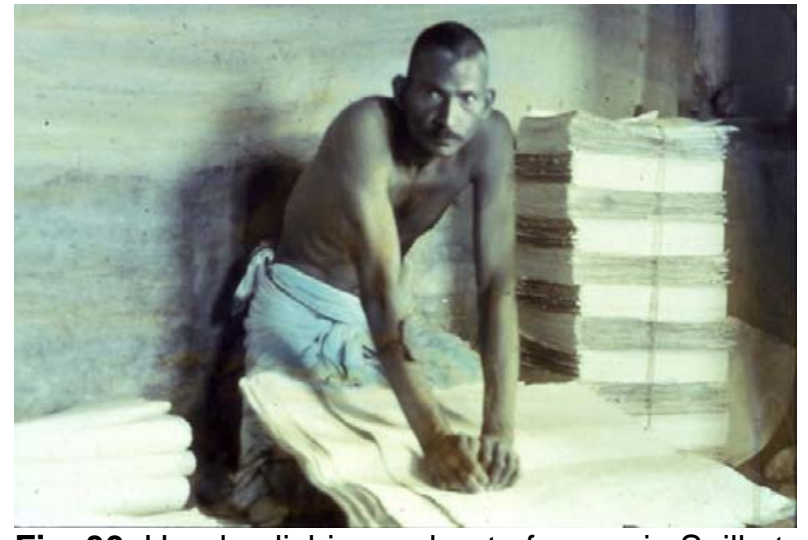

Fig. 30. Hand polishing a sheet of paper in Sailkot, Punjab, India. Photo taken by Dard Hunter, from the collection of the Robert C. Williams Paper Museum
The rubbing action can be compared approximately to what happens during a brush calendering operation (Walsh 1967; Harrison 1989). The shearing forces at the paper surface can be expected to locally heat up the material above its glass transition point, allowing it to deform and flatten (Back 1989). When traditional papermakers merely wanted to dislodge foreign objects from the paper surface, without the polishing, a light rubbing with pumice stone could be used (Hunter 1939).

\section{Calendering with a glazing hammer}

But rubbing paper by hand is laborious, tedious work. So eventually papermakers in Germany came up with a radically different solution, using waterpower to repeatedly strike the surface of the paper with big metal hammers (Turner and Skiöld 1983; Turner 1998). Such operations were effective, but exceedingly noisy.

The next advance came from the Dutch, who developed the practice of passing paper between polished metal rollers under very high pressure (Turner and Skiöld 1983). Historically this would have been considered to be a very different operation in comparison to the use of a glazing hammer. However, due to the very high speeds at 
which modern papermakers currently carry out calendering operations, e.g. well over 100 $\mathrm{km} / \mathrm{hr}$, the effect experienced by the paper entering the nip can be described as a hammerlike squashing effect. Needless to say, such technology has only rarely been used in the case of handmade sheets.

\section{Embossing}

Even though the goal of embossing operations is to make paper bumpy, the way it is done has much in common with the calendering operations just described (Ballinger 1982). Embossing has been used by some papermakers to achieve various low-relief patterns (Turner 1998). The printing of Braille text on paper can be considered to be a form of embossing (Ballinger 1982). On a small scale, embossing can be achieved by pressing paper between a pair of embossing plates, often in the presence of heating (Ballinger 1982). The physics involved in these processes can be understood in terms of the plastic deformation of paper when it is placed under high loads (Castro and OstojaStarzewski 2003; Harrysson and Ristinmaa 2008).

\section{Traditional Printing}

Writing, drawing, and printing on paper have been intimately related to paper's evolution. Three traditional ways of applying text to paper's surface can help to define different periods in paper's development. The three ways are brush application, the use of a quill pen, and letter-press printing.

\section{Brush-printing in the East}

Throughout the earliest period when paper technology was developing, the traditional writing implement in China was the brush-pen, i.e. mao bi. Strict penmanship rules came into practice so that characters could be formed in a recognizable manner, all while maintaining a dignified and even beautiful pattern. As mentioned earlier, the writing traditions need to be understood in the context of the Confucian and Buddhist texts, for which paper was used to a great extent (Hunter 1947; Bloom 2001). The accepted way to record such revered texts was to brush them only one side of a thin, rather absorbent sheet.

\section{A tradition of penmanship in the Islamic world}

When paper technology became adopted within the Islamic world, it was used for another kind of well-developed and often beautifully applied script. Arabic script is cursive, and this is a likely reason why movable type did not develop in the great papermaking centers of Samarkand, Bagdad, and Egypt, for instance (Bloom 2001). However, what did become common was the assembly of pages with text on both sides in the book format, following a tradition that had developed in Christian lands for vellum texts during the $4^{\text {th }}$ century (Bloom 2001).

\section{Development of letterpress printing in the West}

The history of papermaking was affected profoundly by the development of movable type and printing technologies, especially in Germany and Italy. During the 1400s Gutenburg printed several copies of his first Bible on parchment, but presumably

Hubbe and Bowden (2009). "Handmade paper, review," BioResources 4(4), 1736-1792. 1775 
due to limited supplies, the remainder of the print run was executed on paper (Bloom 2001). Because printing technology developed at a time when paper already was available, the methods and inks were adapted to the medium. The earliest paper used for such printing was vellum-type, meaning that it had a hard surface that was well suited for writing with a quill pen. Softer paper grades became more popular with the growth of letter-press printing.

\section{PERSONALITY AND ART FROM HANDMADE PAPER}

Some excellent books have focused on handmade papermaking as a form of artistry (Kern 1980; Webb 1982; Turner and Skiöld 1983; Wolfe 1990; Plowman 1997; Lafosse 1998; Potter 1999; Ramsay 1999; Reimer-Epp 2000; Lee 2001; Ackerson 2003; Lorenté 2004; Bautista 2006). In this section we will consider ways in which such initiatives have been encouraged or constrained by the inherent nature of the materials (Webb 1982).

To begin with, a distinction needs to be made between paper art and handmade papermaking in general. The traditional papermaker does not ordinarily see herself or himself as an artist, even if the products may include some rather exotic applications, e.g. umbrellas and fans (Jugaku 1959). In their day-to-day work, the traditional papermaker usually strives to achieve uniformity and repeatability (Reynard 2001). But in the hands of an artist, considerable creativity can go into both the production of paper art objects, and also the modification of handmade paper in the service of art. For example, art can "happen" when paper is folded and bended to create an object that communicates in a unique way with the viewer (Studley 1977; Heller 1980; Turner and Skiöld 1983). As noted by Bautista (2006), the paper artist sets out to spend some time working with the medium, giving rein to wide, free-form ideas. Thus the difference between paper craft and paper art lies in the expressive intent of the maker and the absence of specific rules (Heller 1978; Bell 1981).

Paper also plays a role as the substrate for painted or drawn images. In such applications it is important to appreciate the effects of the substrate's characteristics on the artistic product (Webb 1982). Paper's receptivity toward liquids will affect the execution of watercolor painting, as well as artistic calligraphy. Many artists show a preference for textured papers, upon which the grain of the sheet can show up in the image that is produced. This can be particularly the case with charcoal drawings.

As a practical matter, a traditional papermaker knows that their product exhibits considerable personality, i.e. characteristics that make it possible to recognize that a sheet belongs together with a set of similar sheets, but also ways in which each sheet is recognizably different (Heller 1978). There are some telltale signs that a sheet probably has been made by traditional methods. For instance, handmade papers form Japan, i.e. washi, can be expected to have a smooth side, the side that was facing the smooth surface upon which it was dried (Hughes 1978; Turner 1998). Though the rough "deckle edge" can be simulated during mechanized papermaking, one more often associates it with handmade products (Turner and Skiöld 1983). The same authors provide an admirably detailed list and explanations for innumerable blemishes that can mark handmade paper

Hubbe and Bowden (2009). "Handmade paper, review," BioResources 4(4), 1736-1792. 1776 
products. Heller (1978) makes the point that papermaking is one of those crafts for which an individual can control essentially the whole process, and for that reason it may be possible to discern the maker's idiosyncrasies by looking at the result.

In contrast to typical traditional papermaking practices, some artistic papermakers set out to emphasize the idiosyncratic nature of their materials. Lorenté (2004) provides many color images showing paper sheets with visible leaves, as well as incompletely separated fibers. In fact the work of Lorenté is notable for completely leaving out any refining of the fibers, preferring instead that the final product should show off the contrasting native character of different plant materials. Cedran (2001) has edited an impressive description and collection of Brazilian handmade paper samples in which well-refined pulp is combined with selected long fibers or other natural inclusions, and various processing chemicals such as carboxymethyl cellulose are used to achieve good dispersion and bonding within the sheet.

In many respects paper can be considered a challenging, if not daunting medium in which an artist might chose to work. Perhaps because typical papermaking fibers are 50 or more times or more as long as they are thick, it can make a huge difference just how they are made to come together; for instance, two balls of wet pulp cannot be squeezed together with as if they were lumps of clay. An initial attempt to make threedimensional objects out of wet papermaking fibers may show signs of shrinkage during drying (Corte and Herdman 1975), and it is likely that cracks will develop.

The word "design" is often used to define a domain of activity that lies somewhere between that of a skilled craft and true artistry. It might be said that design involves the embodiment of an artistic idea. The papermaker can employ a wide variety of tried-and-true strategies (see Zeier 1980; Ballinger 1982; Plowman 1997; Ramsay 1999; Lee 2001; Garner 2006) in order to reproduce the creative concept.

\section{Artistic Strategies for which the Medium Appears Well Suited:}

Many strategies can be used to achieve artistic effects that involve handmade paper (Hiebert 2000). Some of these strategies can be used either when forming the paper or to modify the paper after it has been formed.

\section{Effects during forming}

In the most traditional procedures for hand papermaking the craftsperson takes pains to achieve a uniform suspension of fibers. But what if they did the opposite? To achieve different effects papermakers can add readily visible objects to the suspension, e.g. flower petals, leaves, tinsel, bits of torn paper, or long fibers having a contrasting color (Studley 1977; Kern 1980; Turner and Skiöld 1983; Mcfarlane 1993; Reimer-Epp 2000). When inclusions are added to the fiber suspension, the position of such objects in the final paper can depend on random events. Thus, the artist who wishes to exercise greater control of positioning can choose to place the objects on the wet paper immediately after it has been formed (Plowman 1974). A possible advantage of such direct placement is that the added objects will be on top of the sheet, and thus clearly visible. On the other hand, the objects added after sheet formation do not become as well integrated into the sheet, and there can be a greater danger that they later become detached. 
Another artistic effect that can be achieved during the forming process itself is called "cloud paper" (Potter 1999). Cloud paper samples show the subtle appearance of a wave, composed of fibers of a contrasting color. The effect is achieved by first dipping the mold in a vat of fibers having the background color. Then, after the water has been drained, the mold is dipped slightly into a vat that contains the fibers having the foreground color. The mold is tilted at a critical moment to allow a wave of fibers to slump forward, and the forward motion becomes arrested somewhat unevenly as water drains through the screen. This effect depends on such factors as subtle variations in the permeability of the initial fiber mat, a tendency of the fiber suspension to immobilize in a semi-random pattern due to chance entanglements, and the hydrodynamics and eddy formation within flowing fiber suspensions.

\section{Layering}

The application of various visible objects to the wet paper surface, immediately after its formation, can be considered as an example of "layering." But there are additional ways that layering effects can be achieved at that point in the process. For instance, a colored fiber suspension can be squirted onto the surface of the sheet, almost in the manner that one might apply lettering or a design to the icing of a cake (Kern 1980; Plowman 1997; Lafosse 1998; Turner 1998; Ackerson 2003). Related effects can be achieved by pouring or squirting of a fiber suspension having a contrasting color (Potter 1999; Hiebert 2000). As noted by Turner (1998), these effects require a bold approach; the tendency of cellulosic fibers to remain joined in a floc structure limits the fineness of the effects that can be achieved.

\section{Marbling}

There is a long tradition of papermakers applying distinctive colored effects on paper's surface by a process called marbling (Woolnough 1881; Kern 1980; Wolfe 1990; Soteriou 1999; Bloom 2001). The method apparently was invented in Japan, but later avidly practiced by the Persians (Bloom 2001), and also in the west, especially for the

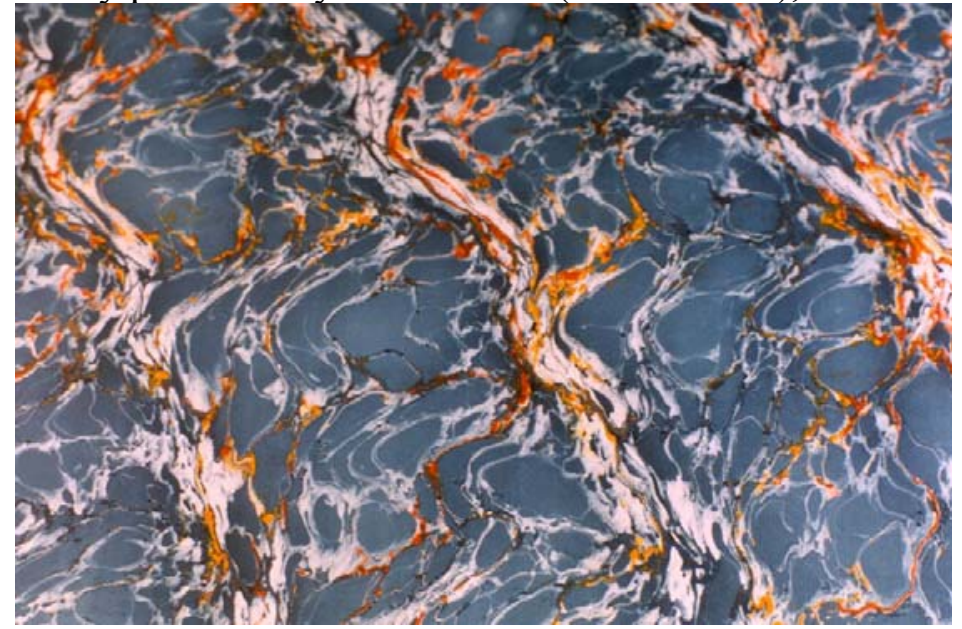

Fig. 31. Marbling sample from the collection of the Robert C. Williams Paper Museum linings of book covers. Marbling is achieved by dissolving water-insoluble ink solutions in mineral oil and then spreading the ink solution onto the surface of aqueous solutions that may contain gelatin or neri as a thickener. The colors on the water surface then can be distributed with a coarse comb or by other means, e.g. by swirling with bristles, using a fan to move the water, or an eye dropper. 
Surfactants can be added at different levels to change the nature of the patterns that result, and it is clear that the effects are governed by surface tension forces (Wolfe 1990). For artists wanting to achieve more purposeful control, the Japanese term suminagashi means that the artist uses water-insoluble dye solution to draw onto the surface of the thickened water solution, and thereafter the pattern is transferred to the paper (Woolnough 1881; Wolfe 1990).

The pattern is transferred to the paper surface by gently laying the sheet down on top of the water and lifting it back out, spraying with clean water, and drying the paper thoroughly while pressing it to keep it flat. A "belly-first" placement of the paper on the liquid surface has been recommended. Some marblers instead immerse the paper into the solution upon which the colors are floating and then draw it out again (Wolfe 1990). Plowman (1997) suggests wallpaper paste as a practical thickener to be used by modern paper marblers.

\section{Collage}

Collage is an artistic effect achieved by placement of pieces of paper, which may have print images on them (Ballinger 1982; Plowman 1997; Turner 1998; Ackerson 2003), with other objects. By juxtaposing torn or cut pieces beside or overlapping each other, the artist can achieve striking contrasts in shade and texture (Turner 1998). For those who want to achieve an effect closer to that of traditional papermaking, the component pieces of paper can be assembled while they are wet, and then dried as one would dry ordinary paper (Turner and Skiöld 1983).

\section{Cut paper}

A rich tradition and many fine masterpieces have been associated with the cutting of paper (Temko 1974, 1982; Ballinger 1982; Longenecker 1985; Berliner 1986). A favorite aspect of this art is the portrayal of stylized silhouette images of landscapes or people. Though most paper cut artists uses scissors, it is also possible to use a sharp knife and a smooth, nonabrasive backing, such as paraffin wax (Temko 1982). When using scissors, Temko recommends holding the scissors in one position and feeding the paper towards the cutting point. The scissors most preferring by papercut specialists have relatively large handles and short blades (see Temko in Longenecker 1985).

Some key attributes required for paper to be used for cutting artistry include stiffness and sufficient tolerance of stretching so that the shearing action of the scissors does not result in breakage adjacent to the cut. As noted earlier in this article, not all cellulosic materials share paper's ability to accept a high-quality cut; indeed, it has been proposed that papyrus was formed into scrolls, rather than made into books, partly because of the poor quality of its cut edges (Bloom 2001). Both paper's stiffness and its flexibility derive from its nano-architecture, which involves combinations of relatively rigid crystalline cellulose regions, joined together by more flexible amorphous regions (Ioelovich 2008). The fibers are all intensively bonded in a three-dimensional structure with hydrogen bonding as a dominant component of the attachments (Nissan et al. 1985). Because the narrow strips produced by a skilled paper cutter can be narrower than the length of a fiber, it is important that the fiber have been refined to a relatively high degree. It has been shown that well-refined fibers can yield paper in which the junctions 
between adjacent fibers are not very much weaker than the fibers themselves (Page 1969; Nanko et al. 1989).

\section{Shifu, textiles made out of paper}

A form of coarse thread or yarn can be prepared by twisting a narrow strip of paper; such yarns then can be used to weave cloth, i.e. shifu (Bunshō 1959; Jugaku 1959; Longenecker 1985; Barrett 2005; Leitner 2005). At various times in the past paper clothing has come into style both in Japan and Europe. Relatively inexpensive and warm paper clothing could be produced from well-starched handmade paper, even without any spinning (Longenecker 1985). As noted by Leitner (2005), paper clothing makes a rustling noise as one walks, reminding the wearer not to take themselves too seriously. Shifu garments, which required yarn-making, were generally associated with the wealthy class. Though shifu garments do not have as high resistance to tear as conventional textiles, they can be quite strong, depending on the quality of the fibers that were used in forming the paper.

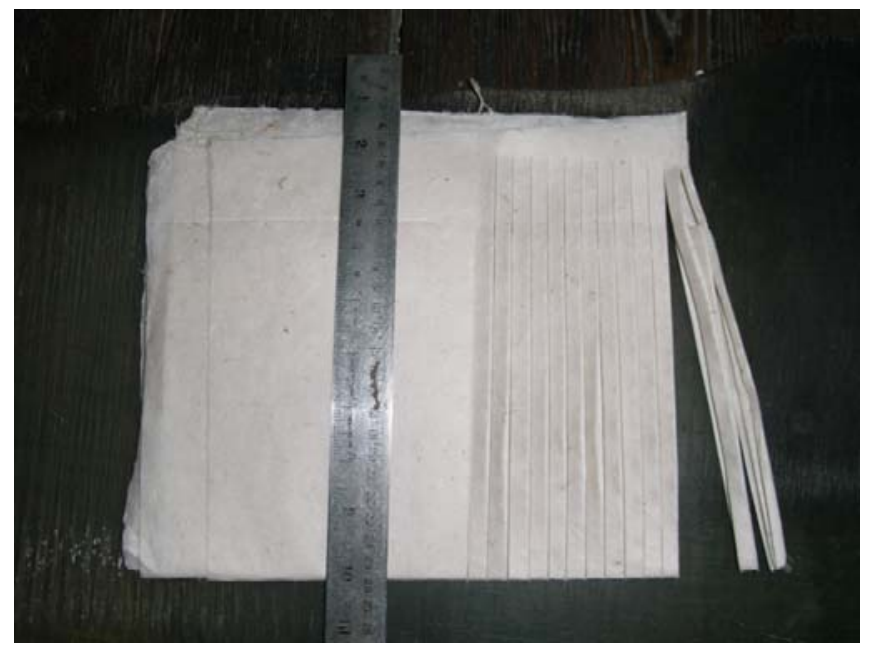

Fig 32. Cutting the sheets into one long strip for shifu, photograph by Deepak Sheestra, Tibet, 2008
To prepare shifu, the traditional craftsperson generally starts by preparing paper sheets having a high degree of fiber orientation in the direction destined to be the lengthwise direction of the yarn (Longenecker 1985). To accomplish this, the pouring and shaking motions all would be back and forth along that axis. The sheets are then carefully cut with the rows of strips no wider than about $2 \mathrm{~mm}$. The cuts, however, do not quite reach the ends of the sheet at any point.

With the sheet still intact, the papermaker can roll it up, then tug on it, repeating this multiple times, until considerable twisting already is apparent within the strips. Then the edges of the paper are carefully torn on alternate sides to give a single, long strip. This procedure can yield a strip more than 200 meters long from one sheet. This strip is loaded onto a spinning wheel.

One of the keys to spinning paper strips into yarn is to carefully adjust the moisture content (Longenecker 1985). If the paper is too dry, the material will not have sufficient ability to stretch, and it will tend to fail during spinning. On the other hand, if the paper is too wet, there is a limit beyond which it just turns back into pulp. The relationship between paper's moisture, its tolerance of stretching, and its tensile load to failure have been discussed in terms of a balance between capillary forces (especially at high moisture content) vs. hydrogen bonding, which becomes dominant as a bonding force in dry paper (Lyne and Gallay 1954). 


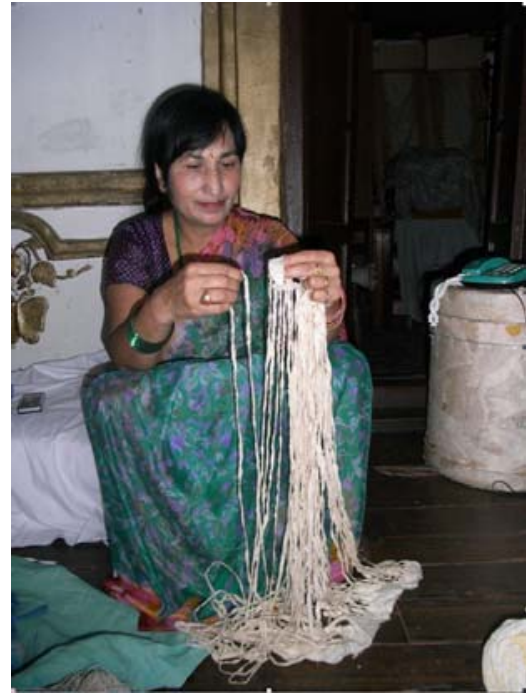

Fig. 33. Joining the paper strips together to make the shifu, photo by Deepak Sheestra, Tibet, 2008

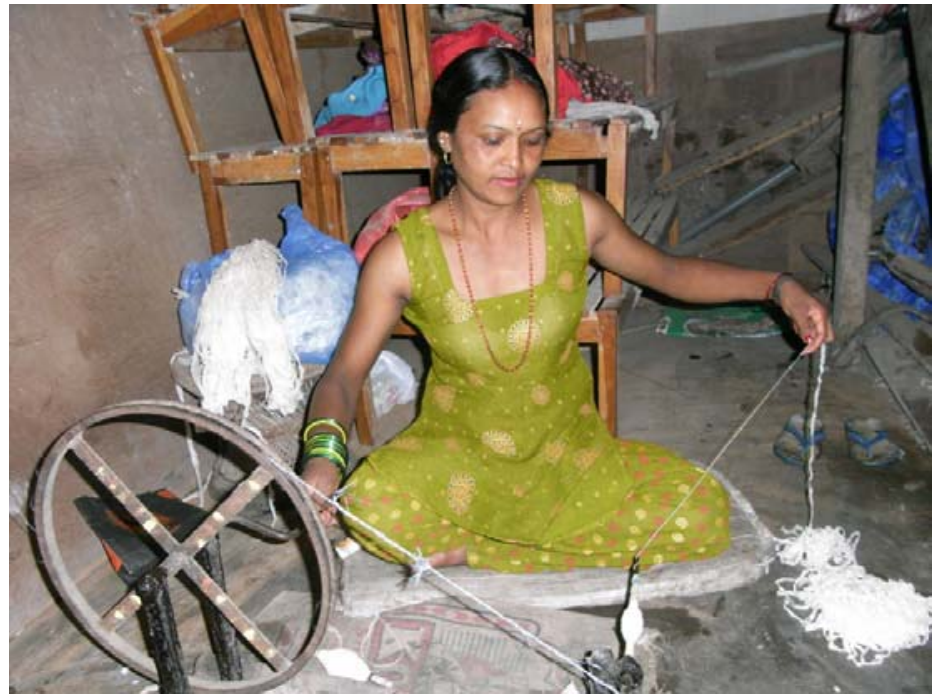

Fig. 34. Spinning the paper strips into yarn, photo by Deepak Sheestra, Tibet, 2008

\section{Paper Folding}

Paper folding, (origami in Japan), has been highly developed as an art form, craft, and popular pastime (Temko 1974; Longenecker 1985; Aytüre-Scheele 1986; Kenneway 1987; Lafosse 1998). Doves and other three-dimensional objects created by folding paper have become part of our culture. The three unofficial rules of traditional Japanese origami are never to use glue, never to un-make a fold, and to prepare three-dimensional objects in such a way that they can be folded flat for storage and transportation (Temko 1974). Another trick of the trade is to run one's finger down each fold to make it sharp (Aytüre-Scheele 1986). As shown by Jackson (1996), curved creases can create interesting three-dimensional effects. Recently the field or origami has been entered by mathematicians, as well as by scientists interesting in the folding of DNA protein chains in the formation of enzyme structures (Cipra 2001).

One of the essential features that makes origami possible is paper's ability to hold a crease (Zeier 1980; Ballinger 1982). Kenneway (1987) noted that certain intriguing origami effects, such as the flapping of a paper dove's wings, depend critically on paper's elastic nature. As in the earlier discussion of embossing, the folding of paper involves locally exceeding the material's elastic deformation limit (Carlsson et al. 1982; Hine 1987; Xia et al. 2002). In addition, some of the inter-fiber bonding is broken when paper is creased, greatly decreasing the force needed to bend the paper again along the same line. Figure 35 illustrates the ways that fiber bond failure, delamination, and buckling can play a role in the irreversible creasing of dry paper. 

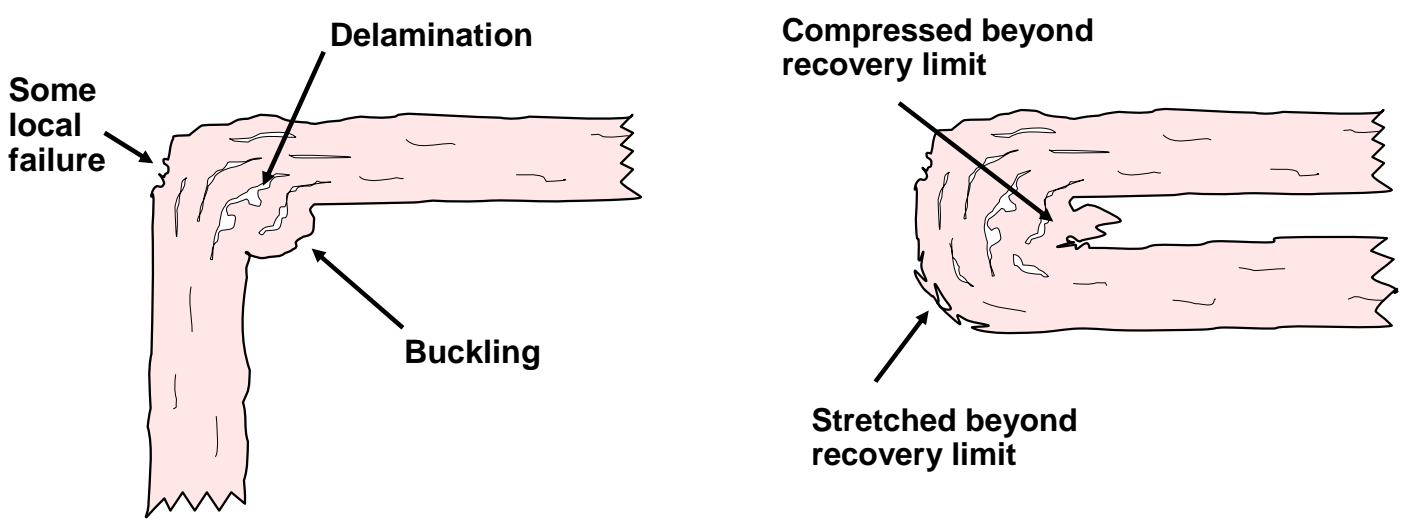

Fig. 35. Irreversible processes that take place during creasing of dry paper. Left: Illustration of partial failure in tensile mode (outside of fold), delamination, and buckling (inside of fold) during initial creasing at 90 degrees. Right: Further irreversible changes upon 180 degree creasing.

Pop-up books

Though pop-up books have a special role and charm all their own, they are closely related to origami in terms of the role of paper. Excellent descriptions of pop-up technology and art are available (Ballinger 1982; Birmingham 2000). Essentially all effects used in a typical pop-up book are derived from three basic systems of folds, the $\mathrm{V}$ fold, the parallelogram, and the 45-degree fold (Birmingham 2000), though often they look different due to imaginative cutting and printing.

\section{Three-Dimensional Forming of Paper}

The various effects discussed so far have involved various modifications of flat paper sheets (see especially Zeier 1980; Jackson 1996). More three-dimensional effects become possible if paper is rewetted, or if paper pulp is used to sculpt, cast, or conform to a frame.

\section{Papier-mâché}

Paper can be used to form various shapes if suitably small pieces are wetted and pasted together (DeVoe 1971; Temko 1974; Lafosse 1998; Turner 1998). The term papier-mâché can be roughly translated as "chewed paper," presumably because the original paper becomes destroyed to a certain extent (DeVoe 1971). Thus, the craft might be properly described as molding with multiple layers of partially pulped paper. A dilute starch solution is often used to soak the paper scraps so that the final structure will have a high degree of bonding. A trick of the trade is to form a paper shell around a selected three-dimensional object, let it dry thoroughly, then cut it into two halves with a sharp knife. The two halves then can be glued back together and the form can be used again (DeVoe 197). 


\section{Sculpting}

Sculpting by direct use of cellulosic pulp can be particularly challenging, due to the uneven drying of thick objects and their tendency to shrink and crack. Toale (1983) recommends the use of cotton fibers for such purposes, due to their relatively low tendency to shrink upon drying. Refining of the pulp should be minimized in order to minimize shrinkage (Heller 1978). Another strategy involves layering paper pulp fairly evenly over the surface of a three-dimensional form that has been placed on a vacuum table (Turner 1998). The table is then covered by a flexible plastic sheet, and the vacuum is applied, squeezing the pulp against the form. Potter (1999) recommends the use of a sponge to partially dewater the pulp layer as it is being applied to the mold, and also the use of talcum powder to make it easier to remove the formed piece after it has dried.

\section{Casting}

The term casting implies that a relatively thick suspension of fibers is applied to the convex surfaces of a prepared mold (Studley 1977; Kern 1980). Sometimes heat is applied to aid in drying (Kern 1980). Again, a key to success seems to lie in the preparation of relatively thin layers (Plowman 1997). The smooth surfaces that can be achieved by casting are no-doubt related to smoothing effects that are achieved when washi papers are dried against polished wood (Turner 1998); in both cases the fibers appear to be held strongly onto the surface by capillary forces, at least until the last remnants of water films have evaporated. Paper also can be cast on the surface of textured, three-dimensional objects, such as baskets (Stearns 1992), yielding attractive visual effects.

\section{Shrinkage around a frame}

Some interesting effects can be achieved if the wet sheets of freshly formed paper are folded around wire frames or solid shapes such as bowls, and then dried (Toale 1983; Potter 1999; Heibert 2000). For instance, this approach can be used to prepare a paper drum, the tension and timbre of which will depend on the relative humidity. If the wet paper is wrapped around suitably narrow wires, shrinkage of the paper during drying can actually bend the wires. Well refined abaca fibers are especially recommended for uses where a high degree of shrinkage is desired (Potter 1999). To maximize this effect, the abaca fibers are extensively, but gently refined. Presumably, refining causes the fibers to swell, especially in their cross-direction. During the drying process the cross-directional shrinkage of the fibers will tend to crimp other fibers within their areas of bonding, resulting in an effective shortening of the fibers and overall shrinkage in the plane of the sheet (Page and Tydeman 1962; Gallay 1973; Uesaka and Qi 1994). In related work, it has been shown that fibers having a high microfibril angle within the predominant S2 layer of the cell wall tend to have a high tendency to change their dimension as a result of changing humidity (Courchene et al. 2006), and one might expect such fibers also to shrink considerably during drying. 


\section{CLOSING COMMENTS}

\section{Hand papermaking in the school}

Perhaps because most of the materials used in papermaking are quite safe (with the exception of pulping liquors, as well as hot irons, that are sometimes used for drying), many teachers and camp counselors, etc., enjoy opportunities to have students make paper (Johnson 1958; O'Reilly 1993; Smith 1995; Fetters 2000). Suitable equipment can be either purchased or built in a simple way (O'Reilly 1993; Fetters 2000). While papermaking demonstrations and workshops are often directed at elementary-school-age kids, high-school

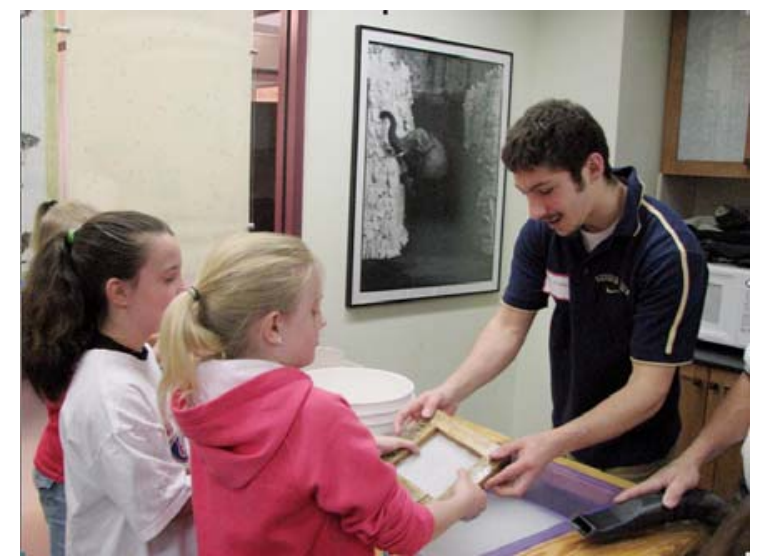

Fig. 36. Papermaking workshop at the Robert C. Williams Paper Museum, 2009 students in a chemistry lab can learn a lot from papermaking. In the latter case, attention should be paid to explaining the bonding mechanisms and the chemical nature of fibers, and it helps to challenge groups of students in a competition to maximize pre-selected measures of quality.

\section{Therapeutic aspects of hand papermaking}

In addition, whether or not one is a serious papermaker, the craft can have a therapeutic aspect (Hope 1989). Bautista (2006) encourages the paper artist to immerse one's whole self in working with the medium, to the extent that other worries are set aside. That certainly has been the experience of the authors, and we hope that the present article might interest at least some of our readers to employ the combination of patience, inquisitiveness, and appreciation that has been shown by traditional papermakers through the ages.

\section{Enduring lessons from the traditional papermakers}

A final bit of wisdom can be gained from reading the accounts of traditional papermaking through the ages. That is, all too often papermakers have assumed that their own methods were the only methods for proper papermaking. History teaches otherwise; there are many valid ways to make paper, and papermakers through the ages have tended to gravitate towards a number of workable strategies. On the one hand, it is admirable if each of us strives to be creative. However, we make a mistake when we neglect to pay attention to what others have done before. Traditional papermakers have, through many years of trial and error, figured out some of the most effective ways to deal with the chemical nature and microstructure of natural fibers. 


\section{ACKNOWLEDGEMENTS}

The authors would like to acknowledge the following individuals for providing helpful suggestions and corrections: Doug Stone, Suki Hughes, Brian Queen, Peter Thomas, Nicholas Basbanes, and Sydney Koretsky, as well as proofreading assistance from Fran Rottenberg.

\section{LITERATURE CITED}

Ackerson, D. (2003). Handmade Paper Collage, Sterling Publishing Anon. (1962). A History of Paper, Fraser Paper Ltd., New York.

Arney, J. S., and Chapdelaine, A. H. (1981). "A kinetic study of the influence of acidity on the accelerated aging of paper," in Williams, J. C. (ed.), Preservation of Paper and Textiles of Historic and Artistic Value II, Adv. Chem. Ser. 193, Amer. Chem. Soc., Washington, DC, Ch. 14, 189-204.

Aytüre-Scheele, Z. (1986). Paperfolding Fun. Origami in Color, Gallery Books, W. H. Smith, Publ., New York.

Back, E. L. (1989). "Development of paper gloss in hot calendaring and brushing," in Fundamentals of Papermaking, Baker, C. F. (ed.)/Trans. 9th Fundamental Res. Symp. (Cambridge), Vol. 2, Sept., 1989, 1027-1054

Baker, C. A. (2000). By His Own Labor. The Biography of Dard Hunter. Oak Knoll Press, New Castle, DE

Baker, C. F. (1995). "Good practice for refining the types of fiber found in modern paper furnishes," Tappi J. 78(2), 147-153.

Ballinger, R. A. (1982). Design with Paper in Art and Graphic Design, Van Nostrand Reinhold Co., New York.

Barrett, T. (1989). "Early European papers / contemporary conservation papers: A report on research undertaken from fall 1983 through fall 1987. The Paper Conservator 13.

Barrett, T. (1991). "New developments in nagashizuki," Hand Papermaking 1(1), 7-9.

Barrett, T. (1991). "Optimum fiber separation for nagashizuki papermaking," Hand Papermaking 6(2), 12-14.

Barrett, T. (1992). "Evaluating the effect of gelatin sizing with regard to the permanence of paper," Conference Papers, Institute of Paper Conservation, Worchester, MA, 228233.

Barrett, T., and Mosier, C. (1995). "The role of gelatin in paper permanence," J. Amer. Inst. Conservation (Fall/Winter), 173-186.

Barrett, T. (2005). Japanese Papermaking: Traditions, Tools, Techniques, Floating World, Warren, CT.

Barrow, W. J., Research Laboratory (1967). Permanence / Durability of the Book - VII. Physical and Chemical Properties of Book Papers, 1507-1949, Publ. W. J. Barrow Res. Lab., Inc., Richmond, VA.

Bautista, T. (2006). Collage Unleashed, North Light Books, Cincinatti.

Bell, L. A. (1981). Plant Fibers for Papermaking, Liliaceae Press, McMinnvelle, OR. 
Bell, L. A. (1983). Papyrus, Tapa, Amate \& Rice Paper: Papermaking in Africa, the Pacific, Latin America \& Southeast Asia, Liliaceae Press, McMinnville, OR.

Berliner, N. Z. (1986). Chinese Folk Art, New York Graphic Soc. Book, Little, Brown and Co., Boston.

Biggs, S., and Messerschmidt, D. (2005). "Social responsibility in the growing handmade paper industry of Nepal," World Devel. 33(11), 1821-1843.

Birch, L., et al. (1964-1965). The Story of Paper, Commissioned by The Dow Chemical Co., (one of 1250 copies made).

Birmingham, D. (2000). Pop-Up. A Manual of Paper Mechanics, Tarquin Publ., Stradbroke, UK.

Bloom, J. M. (2001). Paper Before Print. The History and Impact of Paper in the Islamic World, Yale Univ. Press, New Haven.

Blum, A. (1934). On the Origin of Paper, R. R. Bowker Co., New York.

Borchers, H., Liccione, C., and Windsor, T. (2006). Handmade Paper Jewelry. 40 Beautiful Projects to Make and Wear, Chapelle.

Bright, D. A., Hodson, P. V., Lehtinen, K. J., McKague, B., Rodgers, J., and Solomon, K. (2000). "Use of chlorine dioxide for the bleaching of pulp: A re-evaluation of ecological risks based on scientific progress since 1993," Pulp Paper Can. 101(1), 53-55.

Bunshō, J. (1959). Paper-making by Hand in Japan, Meiji-Shobo Publ., Ltd., Tokyo.

Campbell, W. B. (1959). "The mechanism of bonding," Tappi 42(12), 999-1001.

Carlsson, L., Fellers, C., Westerlind, B., and Backlund, J. (1982). "Finite-element analysis of the creasing and bending of paper," Svensk Papperstidning 85(15), R121R126.

Castro, J., and Ostoja-Starzewski, M. (2003). "Elasto-plasticity of paper," Intl. J. Plasticity 19(12), 2083-2098.

Cedran, L. (ed). (2001). Papel Emoção e Historia, Clube Latino Americano de Papeleiros, Associação Brasileira de Celulose e Papel (ABCTP), Sao Paulo, Brazil.

Chen, G. C. I., and Scott, W. E. (1984). "Relative effects of wet end chemical variables on the strength of acid and alkaline papers," Tappi J. 67(11), 94-96.

Clapperton, R. H. (1934). Paper. An Historical Account of its Making by Hand from the Earliest Times Down to the Present Day, The Shakespeare Head Press, Oxford.

Cipra, B. A. (2001). "In the fold: Origami meets mathematics," SIAM News 34(8), 1-4.

Corte, H., and Herdman, P. T. (1975). "On the shrinkage of paper during drying," Papier 29(7), 288-295.

Courschene, C. E., Peter, G. F., and Litvay, J. (2006). "Cellulose microfibril angle as a determinant of paper strength and hygroexpansivity in Pinus taeda L.," Wood Fiber Sci. 38(1), 112-120.

Cushing, M. L. (1979). “Surface sizing," In Casey, J. P. (ed.), Pulp and Paper Chemistry and Chemical Technology, $3^{\text {rd }}$ Ed., Wiley, New York, Vol. 3, Ch. 20, 1667-1714.

Cutbush, J. (1990). Early American Papermaking: Two Treatises on Manufacturing Techniques, Oak Knoll Books, New Castle, DE.

Dawson, S., and Turner, S. (1995). A Hand Papermaker's Sourcebook, New York, Design Books. 
De Lalande, J. le Français (1761). The Art of Papermaking. (Translated into English by Richard MacIntyre Atkinson), The Ashing Press, Co. Clare, Ireland, 1976. (copy 119 of 350$)$

DeVoe, S. S. (1971). English Papier Mâché of the Georgian and Victorian Periods, Weslayan Univ. Press, Middletown, CT.

Duschesne, I., and Daniel, G. (1999). "The ultrastructure of wood fiber surfaces as shown by a variety of microscopical methods - A review," Nordic Pulp Paper Res. J. 14(2), 129-139.

Fekete, E. Z., and Waugh, R. W. (1981). "Flat-fiber felts reduce break-in time, improve press performance," Pulp Paper 55(2), 124-127.

Fetters, M. K. (2000). "Papermaking as a Science Activity," Science Activities 37(3), 2834.

Gallay, W. (1973). "Stability of dimensions and form of paper,” Tappi 56(11), 54-95.

Garner, L. (2006). The Complete Book of Papercraft, St. Martin's Press.

Glanville, H., and Thomas, P. (1990). Beer Will Help Your Shake. The Recollections of a Ninety-two Year Old Papermaker, The Alembic Press, ISBN 10: 0907482406; ISBN 13: 9780907482406.

Goto, S. (1953). Japanese Hand-Made Paper, Bijutsu shuppan-sha, Japan (300 copies made).

Hamady, W. (1982). Papermaking by Hand: A Book of Suspicions, Perishable Press, Perry Township, Dane Cty., WI.

Harrison, A. (1989). "Board surface quality improved by brush polishers after calender," Pulp Paper 63(1), 94-95.

Harrysson, A., and Ristinmaa, M. (2008). "Large strain elasto-plastic model of paper and corrugated board," Int. J. Solids Structures 45(11-12), 3334-3352.

Heller, J. (1978). Papermaking, Watson-Guptill, New York.

Hewitt, L. M., Parrott, J. L., and McMaster, M. E. (2006). "A decade of research on the environmental impacts of pulp and paper mill effluents in Canada: Sources and characteristics of bioactive substances," J. Toxicity Environ. Health. Part B-Crit. Revs. 9(4), 341-356.

Hiebert, H. (2000). The Papermaker's Companion: The Ultimate Guide to Making and Using Handmade Paper, Storey Publishing.

Hine, D. J. (1987). "The rigidity flexibility balance in the creasing of paper based boards," Appita 40(5), 375-378.

Hon, D. N.-S. and Shiraishi, N. (2001). Wood and Cellulosic Chemistry, $2^{\text {nd }}$ Ed., Marcel Dekker, New York.

Hope, H. (1989). "The art of hand papermaking as a way of centering healing," Proc. $6^{\text {th }}$ Intl. Conf. Study of Shamanism Alt. Modes Healing, 185-192.

Hori, H. (1991). "Sheet formation and paper machines: Present state of small-scale papermaking in Japan,” Japan Pulp Paper 29(1), 29-37.

Hoyland, R. W., and Field, R. (1976). "Review of the transudation of water into paper," Paper Technology and Industry 17(6), 213,215, 216-219; 17(8), 291-293, 298-299, 304-306.

Hubbe, M. A. (2005). "Acidic and alkaline sizings for printing, writing, and drawing papers," The Book and Paper Group Annual 23, 139-151. 
Hubbe, M. A. (2006). "Bonding between cellulosic fibers in the absence and presence of dry-strength agents - A review," BioResources 1 (2), 281-318.

Hubbe, M. A. (2007a). "Paper's resistance to wetting - A review of internal sizing chemicals and their effects," BioResources 2(1), 106-145.

Hubbe, M. A. (2007b). "Flocculation and redispersion of cellulosic fiber suspensions: A review of effects of hydrodynamic shear and polyelectrolytes," BioRes. 2(2), 296331.

Hubbe, M. A. (2007c). "Water and papermaking. 1. Fresh water components," Paper Technol. 48(1), 18-24.

Hubbe, M. A., Chen, H., and Heitmann, J. A. (2009). "Permeability reduction phenomena in packed beds, fiber mats, and wet webs of paper exposed to flow of liquids and suspensions: A review," BioResources 4(1), 405-451.

Hubbe, M. A., and Heitmann, J. A. (2007). "Review of factors affecting the release of water from cellulosic fibers during paper manufacture," BioResources 2(3), 500-533.

Hughes, S. (1978). Washi, the World of Japanese Paper, Kodansha International, Tokyo, New York, San Francisco.

Hunter, D. (1923). Old Papermaking. Mountain House Press, Chillicothe, OH. (200 copies made).

Hunter, D. (1927). Primitive Papermaking. Mountain House Press, Chillicothe, OH.

Hunter, D. (1930). Papermaking through Eighteen Centuries, William Edwin Rudge, New York.

Hunter, D. (1932). Old Papermaking in China and Japan, Mountain House Press, Chillicothe, $\mathrm{OH}$.

Hunter, D. (1936). A Papermaking Pilgrimage to Japan, Korea and China, Pynson Press, New York. (370 copies made).

Hunter, D. (1937). Chinese Ceremonial Paper, Mountain House Press, 125 copies made; printed on handmade paper from the orient. [copy 18]

Hunter, D. (1939). Papermaking by Hand in India, New York, Prynson Printers.

Hunter, D. (1947). Papermaking. The History of and Technique of an Ancient Craft, Dover, New York.

Jackson, P. (1996). The Art and Craft of Paper Sculpture. A Setp-by-Step Guide to Creating 20 Outstanding and Original Paper Projects, Chilton Book Co., Radnor, PA.

Jansson, A., and Jarnstrom, L. (2005). "Barrier and mechanical properties of modified starches," Cellulose 12(4), 423-433.

Johnson, P. (1958). Creating with Paper, Univ. Washington Press, Seattle.

Jugaku, B. (1959). Paper-making by Hand in Japan, Tokyo, Meiji-Shobo Publ., Ltd.

Kenneway, E. (1987). Complete origami. New York: St. Martin's Press.

Kerekes, R. J., and Schell, C. J. (1992). "Characterization of fiber flocculation regimes by a crowding factor," J. Pulp Paper Sci. 18(1), J32-J38.

Kern, M. E. (1980). The Complete Book of Handcrafted Paper. Coward, McCann \& Geoghegan, New York.

Kjellgren, H., and Engström, G. (2008). "Influence of paper structure on barrier properties of starch-coated greaseproof paper," Nordic Pulp Paper Res. J. 23(1), 8790. 
Klungness, J. H., and Caulfield, D. F. (1982). "Mechanisms affecting fiber bonding during drying and aging of pulps," Tappi J. 65(12), 94-97.

Koops, M. (1801). Historical Account of the Substances Which Have Been Used to Describe Events, and to Convey Ideas, From the Earliest Date to the Invention of Paper. $2^{\text {nd }}$ Ed., Jaques and Co., London.

Koretsky, E. (2009). Killing Green: An Account of Hand Papermaking in China, Legacy Press.

Kurdin, J. A. (1977). “Controversy in thermomechanical pulping," APPITA 30(4), 347351.

Lafosse, M. G. (1998). The Art of Sculpting with Paper. A Step-by-Step Guide and Showcase, Quarry Books, Gloucester, MA.

Lee, C. K. (2001). Papermaking. Beautiful Papers \& Projects to Make in a Weekend, The Weekend Crafter (series), Lark Books Div. of Sterling Publ., New York.

Lee, P. F. W., and Lindström, T. (1989). "Effects of high molecular mass anionic polymers on paper sheet formation," Nordic Pulp Paper Res. J. 4(2), 61-70.

Leitner, C. (2005). Paper Textiles, A\&C Black, London.

Lewis, J. Y. (1983). "Papyrus and ancient writing - The $1^{\text {st }} 100$ years of papyrology," Archaeology 36(4), 31-37.

Lindström, T., and Carlsson, G. (1982). "The effect of carboxyl groups and their ionic form during drying on the hornification of cellulose fibers," Svensk Papperstidn. 85(5), R146-R151.

Longenecker, M. (Curator). (1985). Paper Innovations: Handmade Paper and Handmade Objects of Cut, Folded, and Molded Paper, Mingel Intl. Museum of World Folk Art, La Jolla, CA.

Lorenté, M.-J. (2004). The Art of Papermaking with Plants, Norton, New York.

Lyne, L. M., and Gallay, W. (1954). "Studies in the fundamentals of wet web strength," Tappi 37(12), 698-704.

Lyne, M. B., and Huang, Y. C. (1993). "Measuring acid-base and dispersive interactions with paper surfaces under dynamic conditions," Nordic Pulp Paper Res. J. 8(1), 120 122.

Mason, J. (1963). Paper Making as an Artistic Craft, Twelve by Eight, Leicester, UK.

McComb, R. E., and Williams, J. C. (1981). "The value of alkaline papers for recycling," Tappi 64(4), 93-96.

Mcfarlane, N. (1993). A Paper Journey: Travels among the Village Papermakers of India and Nepal, Oak Knoll Books, New Castle, DE.

McKague, A. B., and Calberg, G. (1996). "Effluent characteristics and composition," In: Dence, C. W., and Reeve, D. W. (eds.), Pulp Bleaching - Principles and Practice, TAPPI Press, Atlanta, Sec. VIII, Ch. 1, 751-765.

McGovern, J. N. (1982). "Bonding in papyrus and papyrus-like mats," TAPPI 65(5), 159162.

Nanko, H., Ohsawa, J., and Okagawa, A. (1989). "How to see interfiber bonding in paper sheets," J. Pulp Paper Sci. 15(1), J17-J23.

Nissan, A. H., Byrd, V. L., Batten, G. L., and Ogden, R. W. (1985). "Paper as an H-bond dominated solid in the elastic and plastic regimes," Tappi J. 68(9), 118-124.

Omae, M. (2005). The Yuzen Japanese Paper, BNN, Inc., Tokyo.

Hubbe and Bowden (2009). "Handmade paper, review," BioResources 4(4), 1736-1792. 1789 
O’Reilly, S. (1993). Papermaking, Thomson Learning, New York.

Orts, W. J., Godbout, L., Marchessault, R. H., et al. (1995). "Shear-induced alignment of liquid-crystalline suspensions of cellulose microfibrils," ACS Symp. Ser. 597: 335348.

Page, D. H. (1969). "A theory for the tensile strength of paper," Tappi 52(4), 674-681.

Page, D. H., and Tydeman, P. A. (1962). "A new theory of the shrinkage, structure, and properties of paper," In Bolam, F. (ed.), Formation and Structure of Paper, Vol. 1, Tech. Sec. British Paper and Board Makers Assoc., London, 397-425.

Patakfalvi, Z. (2005). "La Papeterie St-Armand: Success producing hand-made paper," Pulp Paper Canada 106(9), 19-20.

Pietzcker, E. (2009). "Japanese papermaking - Kami-suki," http://www.druckstelle.info/en/papier.htm.

Plowman, J. (1997). The Craft of Handmade Paper. A Practical Guide to Papermaking Techniques, Knickerbocker Press, New York.

Potter, M. (ed.). (1999). Dieu Donné Hand Papermakers’ Cookbook, Dieu Donné Papermill, New York.

Premchand, N. (1995). Off the Deckle Edge: A Paper-making Journey through India, The Ankur Project, Bombay, India.

Ramasubramanian, M. K., Venditti, R. A., and Katuri, K. C. (2007). "A noncontact sensor for the identification of paper and board samples on a high speed sorting conveyor," APPITA J. 60(5), 366-371.

Ramsay, A. (1999). The Handmade Paper Book, New Holland Publ. Ltd., London.

Reimer-Epp, H. (2000). 300 Papermaking Recipes, Martingale and Co. Pastimes, Bothell, WA.

Reynard, P. C. (2001). "Quality and quantity? - Eighteenth-century acceleration of hand methods of papermaking," in: Slavin, J., Sutherland, L., ONeill, J., Haupt, M., and Cowan, J. (eds.), Looking at Paper: Evidence and Interpretation, 112-121.

Roberts, J. C., Au, C. O., Clay, G. A., and Lough, C. (1987). "A study of the effect of cationic starch on dry strength and formation using C14 labeling," J. Pulp Paper Sci. 13(1), J1-J5.

Schäffer, J. C. (1765-71). Versuch und Muster ohne alle Lumpen oder doch mit einem geringen Zutsatze derselben Papier zu machen, Regensburg, 6 volumes, 82 paper specimens, $13 \times 18 \mathrm{~cm}$.

Schreyer, A. (1988). East-West: Hand Papermaking Traditional and Innovations, Univ. Delaware Library, Newark.

Seth, R. S., Page, D. H., Barbe, M. C., and Jordan, B. D. (1984). "The mechanism of the strength and extensibility of wet webs," Svensk Papperstidn. 87(6), R36-R43.

Smith, G. Z. (1995). Teaching Hand Papermaking: A Classroom Guide, Zpaperpress, Cedar Rapids, IA.

Smook, G. A. (1992). Handbook for Pulp and Paper Technologists, $2^{\text {nd }}$ Ed., Angus Wilde Publ., Vancouver.

Somboon, P., Vuorela, J., Pynnonen, T., and Paulapuro, H. (2009). "Grit segments in TMP refining. Part 1: Operating parameters and pulp quality," APPITA J. 62(1), 3741. 
Soteriou, A. (1999). Gifts of Conquerors. Hand Papermaking in India, Mapin Publ. Pvt. Ltd.

Stearns, L. (ed.) (1992). Papermaking for Basketry and Other Crafts, Lark Books, Asheville, NC.

Stone, J. E., and Scallan, A. M. (1966) "Influence of drying on the pore structures of the cell wall," in: Bolam, R. (ed.), Consolidation of the Paper Web, Vol. 1, British Paper and Board Makers Assoc., 145-174.

Stover, C. A., Koch, D. L., and Cohen, C. (1992). "Observation of fiber orientation in simple shear flow of semi-dilute suspensions," J. Fluid Mech. 238, 277-296.

Stromer, U. (1390). Püchl von meim Geslecht und von Abentewr [Manuscript in the hand of the author], Nürnberg.

Studley, V. (1977). The Art and Craft of Handmade Paper. Van Nostrand Reinhold, New York.

Sturm, L. C. (1718). Völlständige Mühlen Baukunst, Augstburg.

Takeo Co., Ltd. (1979). Handmade Papers of the World.

Taori, K. (2002). Green and Gramin: The Ecofriendly Handmade Paper Industry, Regency Publ., New Delhi.

Temko, F. (1974). Paper. Folded, Cut, Sculpted, Collier Books, New York.

Temko, F. (1982). Chinese Paper Cuts, their History, how to use them, how to make them, China Books \& Periodicals, Inc., San Francisco.

Tindale, T. K., and Tindale, H. R. (1952). The Handmade Papers of Japan. Rutland, VT, Charles E. Tuttle (150 copies made).

Toale, B. (1983). The Art of Papermaking. Worcester, Mass: Davis Publications.

Tsien, T.-H. (1973). "Raw materials for old papermaking in China," J. Amer. Oriental Soc. 93(4), 510-519.

Turner, S. (1998). The Book of Fine Paper, A Worldwide Survey of Mills, Papers, Techniques, and Uses, Thames and Hudson, New York.

Turner, S., and Skiöld, B. (1983). Handmade Paper Today: A Worldwide Survey of Mills, Papers, Techniques, and Uses, London: Humphries.

Ulmar, M., and Norman, B. (1997). "Observations of fiber orientation in a headbox nozzle at low consistency,” Proc. TAPPI 1997 Engineering and Paper Conf., TAPPI Press, Atlanta, 865-873.

Uesaka, T., and Qi, D. (1994). "Hygroexpansivity of paper - Effects of fiber-to-fiber bonding," J. Pulp Paper Sci. 20(6), J175-J179.

Volkov, V. A., and Yur'ev, V. I. (1974). "Effect of humic substances on the brightness of sized paper," Bumazhnania Promyshlennost (5), 6-7.

Walsh, T. F. (1967). "Gloss calendering and brush finishing," Tappi J. 50(7), 48-50A.

Wasser, R. B. (1978). "Formation aids for paper. An evaluation of chemical additives for dispersing long-fibered pulps," Tappi 61(11), 115-118.

Webb, S. (1982). Paper - The Continuous Thread, Cleveland Museum of Art, Indiana Univ. Press.

Weeks, L. H. (1916). A History of Paper-Manufacturing in the United Stated, 1690-1916, Burt Franklin, New York (reprinted 1969).

Weise, U., and Paulapuro, H. (1998). "Relation between fiber shrinkage and hornification," Prog. Paper Recycling 7(3), 14-21. 
Welf, E. S., Venditti, R. A., Hubbe, M. A., and Pawlak, J. (2005). "The effects of heating without water removal and drying on the swelling as measured by water retention value and degradation as measured by intrinsic viscosity of cellulose papermaking fibers," Prog. Paper Recycling 14(3), 1-9.

Wiedenmann, H. G., and Bayer, G. (1983). "Papyrus - The paper of ancient Egypt," Anal. Chem. 55(12), 1220.

Wolfe, R. J. (1990). Marbled Paper. Its History, Techniques, and Patterns, University of Pennsylvania Press, Philadelphia.

Woolnough, C. (1881). The Whole Art of Marbling as Applied to Paper Book-Edges, Etc., George Bell and Sons, London.

Xia, Q. X. S., Boyce, M. C., and Parks, D. M. (2002). “A constitutive model for the anisotropic elastic-plastic deformation of paper and paperboard," Intl. J. Solids Structures 39(15), 4053-4071.

Yan, H. W., Lindström, T., and Christiernin, M. (2006). "Some ways to decrease fibre suspension flocculation and improve sheet formation," Nordic Pulp Paper Res. J. 21(1), 36-43.

Yang, J., Yin, L., Qian, J., Li, B., Li, D., Yang, Y., and Xu, J. (eds.) (2005). A Guide to Hand-made Paper in Yunnan, Yunnan Science and Technology Press.

Zauscher, S., and Klingenberg, D. J. (2001). "Friction between cellulose surfaces measured with colloidal probe microscopy," Colloids Surf. A 178(1-3), 213-229.

Zeier, F. (1980). Paper Construction: Two and Three Dimensional Forms for Artists, Architects, and Designers, Charles Scribner's Sons, New York. 